\title{
Status and Integration of the Gas Generation Studies Performed for the Hydrogen Safety Program- FY 1992 Annual Report
}

\author{
L. R. Pederson \\ D. M. Strachan
}

February 1993

Prepared for the

U. S. Department of Energy under

Contract DE-AC06-76RLO 1830

Pacific Northwest Laboratory

Richland, Washington 99352

\section{MASTER}




\section{Summary}

Waste in Tank 241-SY-101 on the Hanford Site in Washington State generates and periodically releases hydrogen, nitrous oxide, and nitrogen gases. Studies have been conducted at several laboratories to determine the chemical mechanisms for the gas generation and release. Results from these studies are prasented and integrated in an attempt to describe current understanding of the physical properties $c_{i}$ tihe waste and the mechanisms of gas generation and retention.

Existing tank data are consistent with the interpretation that gases are uniformly generated in the tank, released continuously from the convecting layer, and stored in the nonconvecting layer. Tank temperature measurements suggest that the waste consists of "gobs" of material that reach neutral buoyancy at different times. The activation energy of the rate limiting step of the gas generating process was calculated to be about $7 \mathrm{~kJ} / \mathrm{mol}$ but measured in the laboratory at 80 to $100 \mathrm{~kJ} / \mathrm{mol}$. Based on observed temperature changes in the tank the activation energy is probably not higher than about $20 \mathrm{~kJ} / \mathrm{mol}$.

Several simulated waste compositions have been devised for use in laboratory studies in the place of actual waste from Tank 241-SY-101. Data from these studies can be used to predict how the actual waste might behave when heated or diluted. Density evaluations do not confirm that heating waste at the bottom of the tank would induce circulation within the waste; however, heating may release gas bubbles by dissolving the solids to which the bubbles adhere. Solids settling rates and slurry rheological properties are consistent with the hypothesis that the fracture of dendritic sodium nitrite grains is the controlling factor in determining when gas is released.

Gas generation studies on simulated wastes indicated that nitrous oxide and hydrogen yields are not particularly coupled. Other studies suggest that pre-irradiation leads to the formation of some quite reactive but unknown degradation product that may be further degraded thermally. Subcritical heat treatment of simulated waste containing organic constituents conffrms that this approach may have significant value in reducing the production of flammable gases from organic sources.

Solubility studies of nitrous oxide, the most soluble of the principal gaseous products, indicate it is unlikely that dissolved gases contribute substantially to the quantity of gas released during periodic events. Gases appear to be retained in the waste as bubbles attached to solid particles, and studies show that attempting to decouple them is not likely to be fruitful. A more effective strategy might be to lower the yield strength of the nonconvecting layer by mixing, sonication, heating, dilution, or other methods. 


\section{Contents}

Summary $\ldots \ldots \ldots \ldots \ldots \ldots \ldots \ldots \ldots \ldots \ldots \ldots \ldots \ldots \ldots \ldots \ldots$ iii

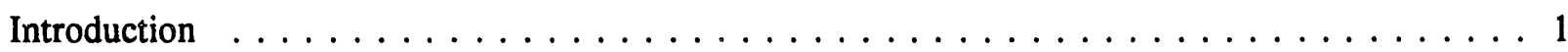

A Summary of Information from Tank $101-S Y \ldots \ldots \ldots \ldots \ldots \ldots$

Waste Simulant Compositions $\ldots \ldots \ldots \ldots \ldots \ldots \ldots \ldots \ldots \ldots \ldots$

Physical Properties of Waste Simulants $\ldots \ldots \ldots \ldots \ldots \ldots \ldots \ldots$

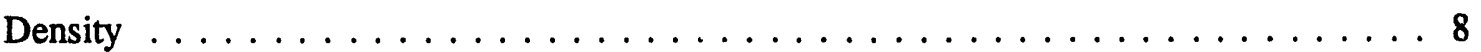

Solids Content and Settling Rates $\ldots \ldots \ldots \ldots \ldots \ldots \ldots$

Rheological Properties $\ldots \ldots \ldots \ldots \ldots \ldots \ldots \ldots \ldots$

Heat Capacity and Thermal Conductivity $\ldots \ldots \ldots \ldots \ldots \ldots$

Gns Generation in Simulated Wastes $\ldots \ldots \ldots \ldots \ldots \ldots \ldots \ldots \ldots \ldots$

Relation of Nitrous Oxide and Hydrogen Production $\ldots \ldots \ldots \ldots \ldots$

Synergism Between Radiolytic and Thermal Processes . . . . . . . . . . . . . 12

Autogenous Hydrothermal Oxidation of Organic Waste Components $\ldots \ldots \ldots \ldots$

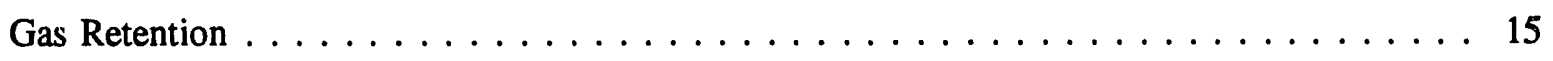

Nitrous Oxide Solubility $\ldots \ldots \ldots \ldots \ldots \ldots \ldots \ldots \ldots$

Gas Bubble-Solid Particle Interactions $\ldots \ldots \ldots \ldots \ldots \ldots \ldots$

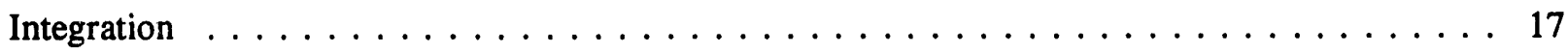

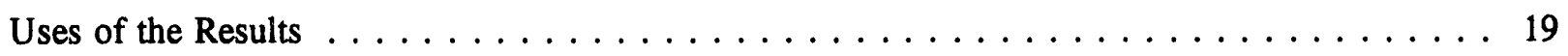

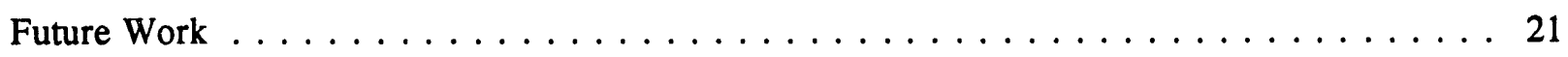

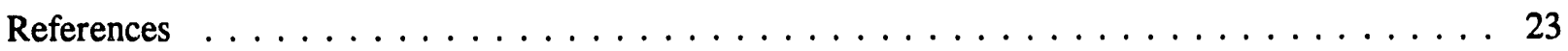


Appendix A - Calculation of an Activation Energy from Tank Data $\ldots \ldots \ldots \ldots \ldots$. . . . .

Appendix B - Definitions of Abbreviations for Organic Species $\ldots \ldots \ldots \ldots \ldots \ldots \ldots$ 


\section{Figures}

1 Surface Level Measurements from Tank 241-SY-101 using the RADAR Gauge

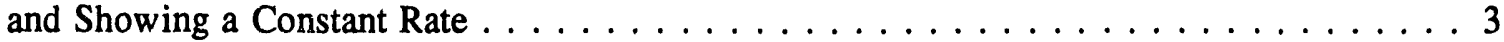

2 Adjusted Surface Level Measurements Showing the Constancy of the Rate of Growth Over the Past $3 \mathrm{Yr} \ldots \ldots \ldots \ldots \ldots \ldots \ldots \ldots$

\section{Tables}

1 Hydrogen Concentrations Measured in Tank 101-SY from Individual Samples

of the Vent Gas . . . . . . . . . . . . . . . . . . . . . . . . 4

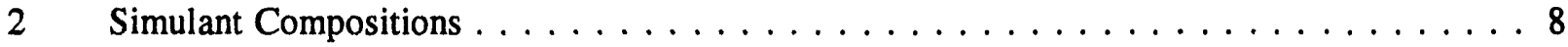

3 Products from the Decomposition of ${ }^{13} \mathrm{C}$-Labeled Organic Species . . . . . . . . . . 13

4 Nitrous Oxide Solubilities in Simulated Tank $101-S Y$ Wastes $\ldots \ldots \ldots \ldots \ldots$

5 Comparison of Gas Generation Data: Gas Composition Results . . . . . . . . . 18

6 Comparison of Gas Generation Results: Kinetic Results . . . . . . . . . . . . . 18 


\section{Introduction}

During the past two years, scientific studies have been carried out to determine the chemical mechanisms for gas generation in a waste tank located on the Hanford Site in Washington State. The waste contained in this tank consists of the residues of various processes used to separate plutonium from spent uranium metal fuel. In the particular case of Tank 241-SY-101 (referred to as Tank 101-SY in this report), gases are generated, both thermally and radiolytically, and partly retained such that the waste swells. Periodically, a portion of the retained gas is released. The gas consists of approximately equal volumes of hydrogen, nitrous oxide, and nitrogen. Because the concentration of hydrogen in the dome space of the tank can often exceed the lower flammability limit (4\%) during some of these releases, a potential safety problem exists that warrants investigation.

In this document, the results from the studies being carried out at Argonne National Laboratory, Georgia Institute of Technology, Pacific Northwest Laboratory, and Westinghouse Hanford Company are analyzed in an attempt to correlate the results from the different studies. There has been no attempt to provide a complete and thorough review of each of the studies; rather, summary information is taken from the publications and the references provided.

In this document, summary information obtained from the instruments in Tank 101-SY is discussed to lay the groundwork for a comparison with the data obtained in the laboratory. A discussion of the chemical properties of simulated wastes emphasizes the composition and the similarity to the aciual waste and includes results from the radiolysis experiments. This discussion is followed by a section on the physical properties of the simulated wastes. After these brief discussions of the laboratory results, an attempt is made tc integrate the results into a consistent understanding of the chemical mechanisms for the generation of the gases in Tank 101-SY. 


\section{A Summary of Information from Tank 101-SY}

Much of what is known about the data from Tank 101-SY has been summarized in a number of documents (Anantatmula 1992; Babad et al. 1992; Reynolds 1991; Ashby et al. 1992). Since those documents have been released, new information has been obtained. Data from the waste level measuring devices have not led to any new conclusions about the rate of gas generation. Johnson (1992) suggested that the data between December 1991 and April 1992 indicate the waste in the tank is cooling and the rate of generation has decreased from a nominal $2.5 \mathrm{~mm} / \mathrm{d}(0.1 \mathrm{in} . / \mathrm{d})$ to $1.8 \mathrm{~mm} / \mathrm{d}$ $(0.07 \mathrm{in} . / \mathrm{d})$. These data have been reanalyzed using a least squares analysis of the linear portions of the data to show that the rate was $2.3 \pm 0.1 \mathrm{~mm} / \mathrm{d}(0.090 \pm 0.004 \mathrm{in} . / \mathrm{d})$ (Figure 1) and has been constant over at least the last $3 \mathrm{yr}$ (Figure 2). ${ }^{\text {(a) }}$ The data suggest that there was a small release of

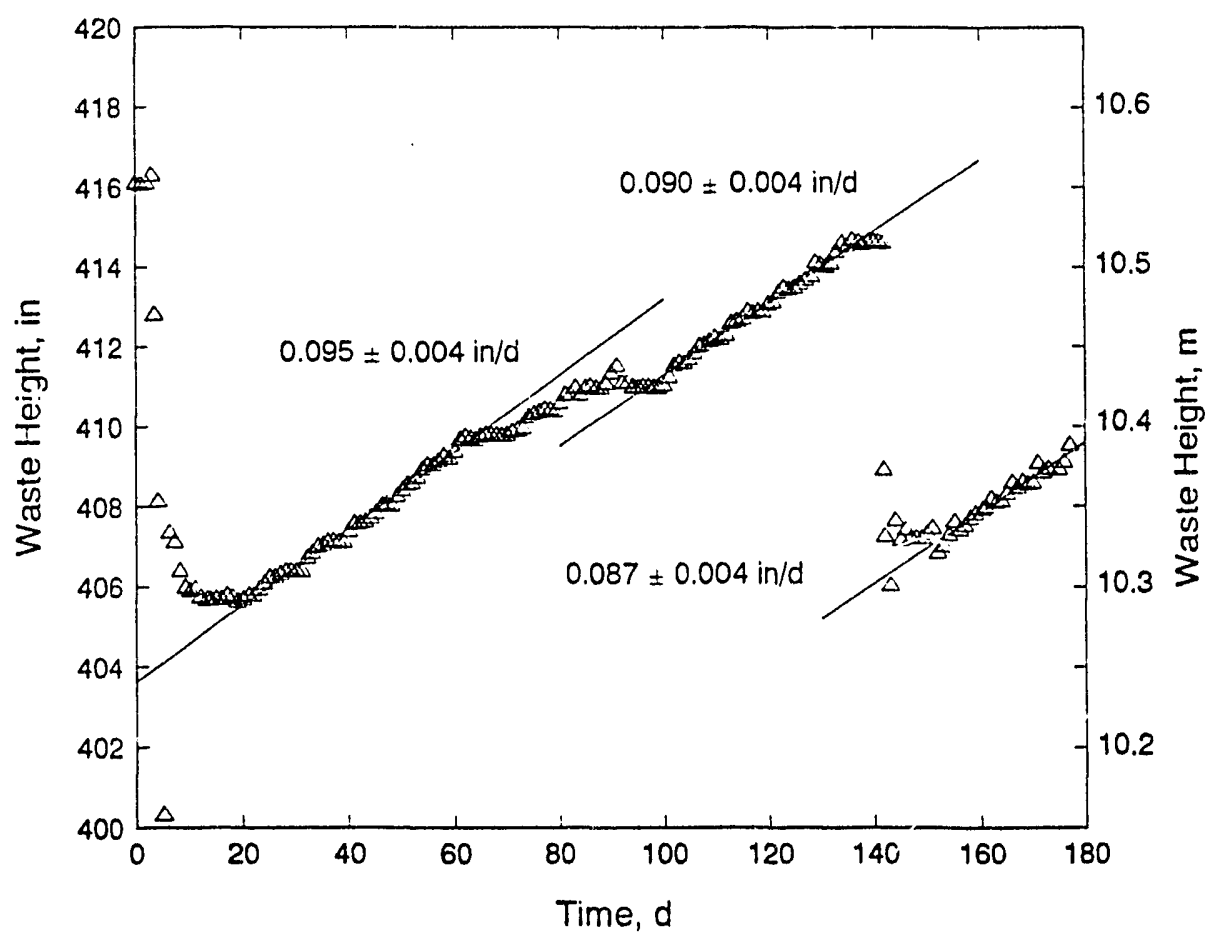

Figure 1. Surface Level Measurements from Tank 241-SY-101 using the RADAR Gauge and Showing a Constant Rate (Day $0=$ December 4, 1991)

(a) The rate is lower than the rates shown in Figure 1 because of an artifact of the data reduction. "Relative waste height" was obtained by adding the level changes due to gas release events to the subsequent level data. Not all of the data are shown to improve clarity. 


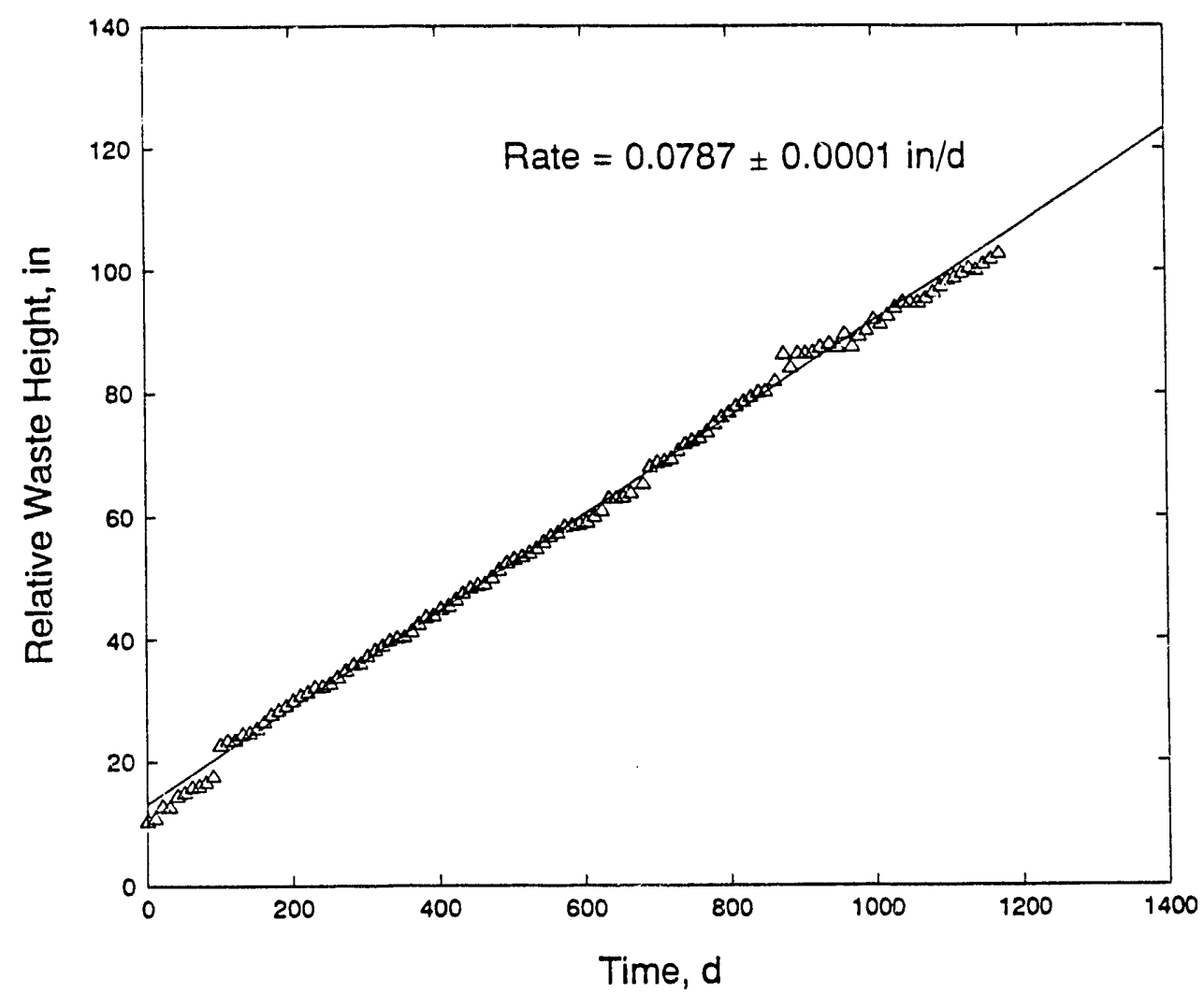

Figure 2. Adjusted Surface Level Measurements Showing the Constancy of the Rate of Growth Over the Past $3 \mathrm{Yr}$

gas about February 1992, such that the waste height did not change. Coincidentally, $\mathrm{H}_{2}$ concentrations measured during that same period showed an increase (Table 1). Unfortunately, the data set is not sufficiently complete to substantiate this conclusion.

Analyses of the level rise in the tank have given rise to the interpretation that the gas in the nonconvecting layer is trapped and not released to the layer above nor to the vent space, while the gas that is generated in the convecting layer is continuously released. For this mechanism it is assumed that the gas generation rate in the two layers is equal, but the gas in the convecting layer is released. Using these assumptions and a ventilation rate of $0.11 \mathrm{~m}^{3} / \mathrm{g}(600 \mathrm{cfm})$, the concentration of hydrogen in the vent space or vent header should be about $45 \mathrm{ppm}$. Recent values for the concentration of hydrogen in the vent header show the gas concentrations to be between $18 \mathrm{ppm}$ and $100 \mathrm{ppm}$ with a mean of $39 \mathrm{ppm}$. These data were obtained with a metal oxide semiconductor detector that is not part of an analytical instrument and has only a limited calibration. However, it is not expected that the measured values are incorrect by more than a factor of two. Thus, the existing data are consistent with the interpretation that has been generally accepted for the last year or so: gases are uniformly generated in the tank, released continuously from the convecting layer, and stored in the 
Table 1. Hydrogen Concentrations Measured in Tank 101-SY from Individual Samples of the Vent Gas

\begin{tabular}{lc}
\multicolumn{1}{c}{ Date } & Concentration, pp \\
\hline January 31, 1992 & 37,36 \\
March 3, 1992 & $104,92,114$ \\
March 5, 1992 & $63,60,68$
\end{tabular}

nonconvecting layer. Any measurable release of gases from the nonconvecting layer result in a corresponding decrease in the waste level or a decrease in the rate of level increase.

During the release of gases from Tank 101-SY in March 1992, the temperatures measured as a function of depth using a single set of thermocouples in the tank did not fluctuate as observed in previous gas release events. In previous events, the temperature as recorded using the fourth thermocouple from the bottom of the tank increased to about $57^{\circ} \mathrm{C}\left(134^{\circ} \mathrm{F}\right)$. In the event in question, the temperature increased to $52^{\circ} \mathrm{C}\left(125^{\circ} \mathrm{F}\right)$ at the time the gases were released. However, after the release, the temperature as measured at the fourteenth thermocouple from the bottom of the tank reached $55^{\circ} \mathrm{C}\left(131^{\circ} \mathrm{F}\right)$. This strongly suggests that, as hypothesized by Allemann (1992), the waste consists of "gobs" of material that reach neutral buoyancy at different times. Thus, while insufficient gas had been generated in the portion of waste nearby the thermocouple tree, at some other position the waste had become neutrally buoyant from the generated gases and, presumably, hotter. This result does not mean that the gas generation rate is different in different parts of the waste, but that the starting point toward neutral buoyancy depends on the history of that portion of the waste.

With respect to the cooling reported by Johnson (1992), there are some confounding data that call this interpretation into question. In the temperature data there are times when the temperature of the entire tank decreased by $0.5^{\circ} \mathrm{C}\left(1^{\circ} \mathrm{F}\right)$ in 1 to $2 \mathrm{~h}$. Since this rapid change in temperature is impossible for the large mass in the tank, the temperature data become suspect. Recently, however, the temperature measurement system, including the thermocouples, connecting lines, and data logger, has been checked and found to be within calibration. Thus, these anomalous readings may be due to the mixing of data from two sources and need to be checked. The original readings should not be discarded, however, because information about the physical mechanism can certainly be gleaned from the data.

Assuming for the moment that the waste in the tank is cooling at $1.5^{\circ} \mathrm{C} / \mathrm{yr}\left(3^{\circ} \mathrm{F} / \mathrm{yr}\right)$ (Johnson 1992) but that the error in the measurement of the rate masks any changes in the rate, one can calculate a maximum activation energy for the process by which gases are being generated in the waste. This activation energy can then be compared with typical activation energies to see if the observed rate and the suspected cooling trend make any sense. Instead of using the cooling rate of the waste, however, it is possible to consider the changes in the rate between gas release events for which there are more data. As shown in Figure 1, the data appear to be linear over much of the time 
cycle between events and in no case does the rate appear to increase. The error in the rate calculated from the data in Figure 1 is less than $5 \%$. This means that the ratio of the rate at the beginning of the 100-day cycle $\left(R_{1}\right)$ and the rate at the end of the cycle $\left(R_{2}\right)$ is $R_{2} / R_{1}=1.05$ and the temperature increased about $6 \mathrm{~K}\left(10^{\circ} \mathrm{F}\right)$. This is consistent with an activation energy for the rate limiting step in the gas generation mechanism of about $7 \mathrm{~kJ} / \mathrm{mol}(2 \mathrm{kcal} / \mathrm{mol})$ [see Appendix A for the details of this calculation]. A similarly low activation energy would be calculated using the cooling rate determined by Johnson (1992). This is a very low activation energy and would not be expected to be the result of a chemical process.

Activation energies have been measured in the laboratory at $80 \mathrm{~kJ} / \mathrm{mol}$ to $100 \mathrm{~kJ} / \mathrm{mol}$ (Ashby in Strachan 1991; Delegard 1980). However, if the activation energy for the rate limiting step in the generation of gases in the tank was $100 \mathrm{~kJ} / \mathrm{mol}$, then during the 100 days between events, the rate at the end of the period and just before a gas release event would be expected to be about 1.4 of the rate at the beginning of the $100-\mathrm{d}$ period. This calculation is based on a $3^{\circ} \mathrm{C}$ increase in the temperature at thermocouple \#4. If the temperature rise is greater, then the ratio of the rates would have to be greater than 1.4 to be consistent with an activation energy of $100 \mathrm{~kJ} / \mathrm{mol}$.

Alternatively, the observed rate could have an activation energy of $100 \mathrm{~kJ} / \mathrm{mol}$ if the mean temperature inciease was much less than that observed in the tank at the position of the thermocouples. The tank is about $23 \mathrm{~m}$ in dianieter and there is one thermocouple tree. There could be temperature inhomogeneiriss in the nonconvection layer that some of the time are not recorded using the single temperature medsurement source. Ev,n in the case where temperature inhomogeneities are indicated by the thermal response of the other thermocouples in the tree, temperatures in the nonconvecting layer increase by several degrees celsius. To address the question of the mean temperature increase, one can assume that the activation energy is $100 \mathrm{~kJ} / \mathrm{mol}$ and calculate how much the temperature would have to change for the rate to stay the same within experimental error. The results from this calculation indicate that if the ratio of the rates was 1.1 , the temperature increase would have to be about $1^{\circ} \mathrm{C}$; at a ratio of 1.05 , the change would be about $0.4^{\circ} \mathrm{C}$. These small temperature changes are simply not observed in the tank. It is thus possible to rule out an activation energy for the rate controlling step being higher than about $20 \mathrm{~kJ} / \mathrm{mol}$.

Diffusion could be the rate controlling mechanism and is consistent with the calculated activation energies based on the data from the level rise and temperature increases between each gas release event. The temperature dependence of the diffusion coefficient in fluids is related to the fluid viscosity. Typical Newtonian fluids have viscosities that exhibit Arrhenius behavior with activation energies in the range of a few kilogoules per mole to a few tens-of-kologoules per mole. Thus, diffusion of some reactive species over a short distance could be the rate limiting step in the mechanism for gas generation from the waste in Tank 241-SY-101, but other mechanisms might also yield the same low activation energies.

Radiolytic reactions or activation could also lead to species with reaction rates having low temperature dependence. The thermal gas generation rate in simulated waste solutions has been found to increase dramatically when the solution has been preirradiated (see Meisel in Strachan 1992b). This implies that a very reactive intermediate species is generated during radiolysis. Although the 
effect of the radiolysis is expected to have a low activation energy, i.e., have little temperature sensitivity, radiolysis is not expected to be the rate limiting step in the processes that yield gas in these solutions. Radiolysis of water does not appear to yield significant amounts of gas from the waste.

\section{Waste Simulant Compositions}

Several simulant compositions have been devised for use in laboratory studies in the place of actual waste from Tank 101-SY. The purpose of each of the simulant recipes was not necessarily to precisely reproduce the composition of the actual waste. Rather, the simulants were designed to aid in the conduction and interpretation of laboratory experiments aimed at determining chemical kinetics and mechanisms responsible for gas generation and retention in the wastes. Simulant compositions currently being used are given in Table 2 (weight percent and approximate molarity). Each composition has been given an alphanumeric code as an identifier.

Two simulant compositions form a slurry at tank temperatures. Simulant SY1-SIM-91A contains the principal inorganic constituents of the actual waste in addition to 0.3 molar organic complexants. This simulant composition was defined by D. L. Herting (WHC) and has been known as the "final word" recipe (Strachan 1992b). Simulant SY1-SIM-92A more closely represents the composition of the wastes in Tank 101-SY. In addition to the principal inorganic components, this simulant contains minor components found in actual wastes, including transition metals, chloride, fluoride, sulfate, and phosphate ions. The composition of this simulant was based on is weighted average of analyses of actual waste core samples obtained during Window " $C$ " (Herting et al. 1992).

Two simulant compositions, SY1-SIM-91B (Strachan 1992b) and SY1-SIM-91C (shown as Solution $P$ in Meisel et al. 1991), have been used in laboratory studies where homogeneous solutions were required. Simulant SY1-SIM-91B contains the principal inorganic components found in SY1-SIM$91 \mathrm{~A}$, but at $70 \%$ of the concentration of the latter. The hydroxide content of this simulant was boosted to prevent precipitation of aluminum hydroxide, however. Simulant SY1-SIM-91C differs from SY1-SIM-91B in that sodium carbonate is absent from the former and the concentration of sodium aluminate is substantially reduced. Homogeneous solutions are necessary to simplify interpretation of chemical kinetics studies performed in the laboratory.

While inorganic waste constituents of actual wastes are reasonably well-reflected in the compositions of the simulants listed in Table 2, organic constituents are not. One obvious reason is that the majority of organic constituents of the actual wastes have yet to be defined. Simulated wastes provide the flexibility of substituting known or anticipated organic components to determine chemical degradation mechanisms. Such mechanistic investigations would not be possible using actual wastes. 
Table 2. Simulant Compositions

\begin{tabular}{|c|c|c|c|c|c|c|}
\hline \multirow[b]{2}{*}{ Component } & \multicolumn{2}{|c|}{ SY1-SIM-91A } & \multicolumn{2}{|c|}{ SY1-SIM-91B } & \multicolumn{2}{|c|}{ SY1-SIM-92A } \\
\hline & WT\% & $\underline{\mathbf{M}}$ & WT\% & $\mathbf{M}$ & WT\% & $\mathbf{M}$ \\
\hline $\mathrm{NaOH}$ & 7.3 & 2.3 & 6.3 & 2.00 & 6.3 & 2.5 \\
\hline $\mathrm{NaAlO}_{2}$ & 11.8 & 2.2 & 8.3 & 1.54 & 10.5 & 2.1 \\
\hline $\mathrm{NaNO}_{3}$ & 20.0 & 3.7 & 14.0 & 2.59 & 12.0 & 2.2 \\
\hline $\mathrm{NaNO}_{2}$ & 14.6 & 3.2 & 10.2 & 2.24 & 17.5 & 4.0 \\
\hline $\mathrm{Na}_{2} \mathrm{CO}_{3}$ & 4.2 & 0.6 & 2.9 & 0.42 & 2.7 & 0.4 \\
\hline Organic & 2.4 & 0.3 & 1.7 & 0.21 & & -- \\
\hline $\mathrm{Na}_{4}$ EDTA & -- & -- & -- & - & 1.6 & 0.066 \\
\hline $\mathrm{Na}_{4} \mathrm{HEDTA}$ & -- & -- & -- & - & 3.3 & 0.14 \\
\hline $\mathrm{NaCl}$ & $\approx$ & -- & -- & - & 2.0 & 0.53 \\
\hline $\mathrm{Na}_{3} \mathrm{PO}_{4}$ & -- & -- & -- & -- & 4.4 & 0.18 \\
\hline $\mathrm{NaF}$ & -- & -- & -- & -- & 0.27 & 0.10 \\
\hline $\mathrm{Cr}\left(\mathrm{NO}_{3}\right)_{3}$ & -- & -- & -- & -- & 2.7 & 0.11 \\
\hline $\mathrm{Cu}\left(\mathrm{NO}_{3}\right)_{2}$ & -- & - & - & -- & 0.0026 & 0.00021 \\
\hline $\mathrm{Fe}\left(\mathrm{NO}_{3}\right)_{3}$ & -- & -- & -- & - & 0.087 & 0.0074 \\
\hline
\end{tabular}

\section{Physical Properties of Waste Simulants}

Densities, solids content, settling rates, rheological properties, heat capacities, and thermal conductivities of waste simulants have been evaluated in laboratory tests using waste simulants. Such data are needed to model gas retention and release phenomena in Tank 101-SY as well as to predict how the actual waste might behave when heated or diluted. Where possible, comparisons between physical properties of actual wastes and simulants have been made.

\section{Density}

Densities for settled solids and supernatant liquid from the waste simulant SY1-SIM-92A were measured as a function of temperature (Bryan and Pederson in Schulz and Strachan 1992). Supernate densities ranged from 1.4 to $1.5 \mathrm{~g} / \mathrm{mL}$ in the temperature range 25 to $80^{\circ} \mathrm{C}$, with no clear trend as a function of temperature within error bounds. Similar behavior has been found for segments of actual waste from the convecting layer of Tank 101-SY. Settled solids densities were typically 1.7 to $1.8 \mathrm{~g} / \mathrm{mL}$, again in reasonably good agreement with certain segments of the actual wastes.

Small increases in supernatant liquid densities with increased temperature were found in carefully controlled laboratory experiments where the supernate was heated in the presence of excess 
solids. This behavior was attributed to partial dissolution of those solids (Pederson and Bryan in Schulz and Strachan 1992). Supernate densities for the simulant SY1-SIM-91A increased from $1.44 \pm 0.02 \mathrm{~g} / \mathrm{mL}$ at $40^{\circ} \mathrm{C}$ to a maximum of $1.52 \pm 0.02 \mathrm{~g} / \mathrm{mL}$ at $85^{\circ} \mathrm{C}$. From these results, heating waste at the bottom of the cank would not be expected to be a viable means of inducing circulation within the wastes. Rather, waste layers would tend to be stabilized by heating. However, since it is believed that gas bubbles adhere to the solids that have slightly hydrophobic surfaces, dissolution of solids as a result of heating would release the adsorbed gas.

\section{Solids Content and Settling Rates}

The fraction of solids present in the waste simulant SY1-SIM-92A as well as rates of solids settling have been measured as a function of temperature and dilution with sodium hydroxide solutions (Bryan and Pederson in Schulz and Strachan 1992b). Weight percents and volume percents of solids present were found to decrease substantially as waste simulants were diluted with 2 molar sodium hydroxide solution. This behavior was expected and desired; with fewer solids present, the extent of gas retention in the wastes should be lessened. No clear trend in the solids content as a function of temperature was found. When the simulants were diluted with 0.1 molar sodium hydroxide, the solids content did not diminish as before. Precipitation of aluminum hydroxide may have offset any increased dissolution of sodium nitrate and sodium nitrite under such conditions. It is known that aluminum hydroxide becomes the preferred phase for base concentrations smaller than approximately 1 molar, whuse solubility decreases rapidly with decreased base content; sodium aluminatc; is the preferred phase for base concentrations greater than that value (Barney 1976). In these experiments, however, the solids were not directly analyzed, so it is uncertain whether the increase in solids content was due to the precipitation of aluminum-containing solids when the diluent was 0.1 molar sodium hydroxide.

Solids were found to settle more quickly as the temperature was increased and as the waste became more dilute (Bryan, Pederson, and Scheele 1992). Temperature had a much greater effect on solids settling velocities for diluted simulants than undiluted compositions. The cause for such behavior is not understood at present. These trends suggest that a specific phase(s) strongly affects settling behavior and is preferentially dissolved in diluted simulants. Sodium nitrite, which can crystallize in the form of dendrites with a high surface area to volume ratio, might be playing a controlling role. Sodium nitrite dendrites have been suggested as the critical component that determines the shear strength of the nonconvecting layer in actual Tank 101-SY wastes (Alleman 1992).

\section{Rheological Properties}

Shear strengths for the waste simulant composition SY1-SIM-92A were determined as a function of temperature following the same procedure used to evaluate actual waste cores (Bryan and Pederson in Strachan 19926). Settled solids from simulated wastes typically gave shear strengths of 1 to $2 \mathrm{kPa}$ (10 000-20 000 dynes $\left./ \mathrm{cm}^{2}\right)$ at room temperature and even lower values at elevated temperatures. These results compare favorably with actual waste segments taken from within or near the convecting 
layer, but are considerably smaller than values obtained for actual crust samples (as high as $25 \mathrm{kPa}$ (250 000 dynes $/ \mathrm{cm}^{2}$ ) at ambient temperatures) or for nonconvecting layer samples (as high as $12 \mathrm{kPa}$ [120 000 dynes $\left.\left./ \mathrm{cm}^{2}\right]\right)$.

It is not clear whether or not the methods used to measure shear strength yielc results that accurately represent the properties of the wastes. Results reported above were derived from the resistance to continuous rotation of vanes inserted into the wastes. Alternately, a paddle-like probe was placed into simulated waste samples heated to approximately $80^{\circ} \mathrm{C}$. The waste was allowed to cool to tank temperatures (ca $55^{\circ} \mathrm{C}$ ) and solids were allowed to crystallize. Shear strengths were determined from the initial force required to move the paddle rather than the resistance to contir: s rotation. Initial shear strengths were considerably larger than those derived from continuous sit ing. Extensive fracture of dendritic sodium nitrite grains initially present in the waste samples may partially account for the difference between initial and later shear strength determinations. Similarly, it may be that the fracture of dendritic sodiu in ritrite grains is the controlling factor in determining when periodic releases of flammable gases occur from Tank 101-SY.

\section{Heat Capacity and Thermal Conductivity}

Average heat capacities and thermal conductivities have been determined for simulated wastes as a function of temperature. Such data are needed to model how he tank waste might respond to localized heat loads. Insight on how actual wastes might respond can be gained using simulated wastes; refinement of experimental methods that can be used to evaluate waste cores in a hot cell environment is also a benefit.

Average heat capacities for SY1-SIM-92A simulated wastes have been measured as a function of temperature. Three separate segments of the waste simulant SY1-SIM-92A were evaluated: supernatant liquid, settled solids, and an integral sample containing both supernate and settled solids. These gave average heat capacities in the temperature range 55 to $80^{\circ} \mathrm{C}$ of $0.62 \pm 0.06,0.53 \pm 0.05$, and $0.40 \pm 0.04$ calories $/ g-k$, respectively. The influence of exothermic dissolution processes is believed responsible for the relatively low value obtained for the integral sample. Clearly, a weighted average of heat capacities of tank waste cores might not accurately reflect the properties of the whole.

Using the line source method (Tye 1969), the thermal conductivity of settled solids in simulated wastes (SY -SIM-92A) was determined. The settled solids consisted of a loosely packed layer above a much smaller layer of relatively densely packed solids. The layer containing loosely packed solids gave a thermal conductivity of $0.641 \mathrm{~W} /(\mathrm{m} \cdot \mathrm{K})$ with a standard deviation of $0.043 \mathrm{~W} /(\mathrm{m} \cdot \mathrm{K})$, based on eighteen separate runs over the temperature range 28 to $79^{\circ} \mathrm{C}$. There was no statistically significant variation in thermal conductivity over that temperature range. The thermal conductivity of densely packed bottom solids was $0.815 \mathrm{~W} /(\mathrm{m} \cdot \mathrm{K})$ with a standard deviation of $0.023 \mathrm{~W} /(\mathrm{m} \cdot \mathrm{K})$ for three runs performed at room temperature.

Thermal conductivities for simulated wastes reported above are within the range of values reported previously for various tank solids (Bouse 1975). Actual tank waste samples reported in that study gave thermal conductivity values from 0.151 to $1.848 \mathrm{~W} /(\mathrm{m} \cdot \mathrm{K})$, with values dependent on 


\title{
Status and Integration of the Gas Generation Studies Performed for the Hydrogen Safety Program- FY 1992 Annual Report
}

\author{
L. R. Pederson \\ D. M. Strachan
}

February 1993

Prepared for the

U. S. Department of Energy under

Contract DE-AC06-76RLO 1830

Pacific Northwest Laboratory

Richland, Washington 99352

\section{MASTER}




\section{Summary}

Waste in Tank 241-SY-101 on the Hanford Site in Washington State generates and periodically releases hydrogen, nitrous oxide, and nitrogen gases. Studies have been conducted at several laboratories to determine the chemical mechanisms for the gas generation and release. Results from these studies are prasented and integrated in an attempt to describe current understanding of the physical properties $c_{i}$ tihe waste and the mechanisms of gas generation and retention.

Existing tank data are consistent with the interpretation that gases are uniformly generated in the tank, released continuously from the convecting layer, and stored in the nonconvecting layer. Tank temperature measurements suggest that the waste consists of "gobs" of material that reach neutral buoyancy at different times. The activation energy of the rate limiting step of the gas generating process was calculated to be about $7 \mathrm{~kJ} / \mathrm{mol}$ but measured in the laboratory at 80 to $100 \mathrm{~kJ} / \mathrm{mol}$. Based on observed temperature changes in the tank the activation energy is probably not higher than about $20 \mathrm{~kJ} / \mathrm{mol}$.

Several simulated waste compositions have been devised for use in laboratory studies in the place of actual waste from Tank 241-SY-101. Data from these studies can be used to predict how the actual waste might behave when heated or diluted. Density evaluations do not confirm that heating waste at the bottom of the tank would induce circulation within the waste; however, heating may release gas bubbles by dissolving the solids to which the bubbles adhere. Solids settling rates and slurry rheological properties are consistent with the hypothesis that the fracture of dendritic sodium nitrite grains is the controlling factor in determining when gas is released.

Gas generation studies on simulated wastes indicated that nitrous oxide and hydrogen yields are not particularly coupled. Other studies suggest that pre-irradiation leads to the formation of some quite reactive but unknown degradation product that may be further degraded thermally. Subcritical heat treatment of simulated waste containing organic constituents conffrms that this approach may have significant value in reducing the production of flammable gases from organic sources.

Solubility studies of nitrous oxide, the most soluble of the principal gaseous products, indicate it is unlikely that dissolved gases contribute substantially to the quantity of gas released during periodic events. Gases appear to be retained in the waste as bubbles attached to solid particles, and studies show that attempting to decouple them is not likely to be fruitful. A more effective strategy might be to lower the yield strength of the nonconvecting layer by mixing, sonication, heating, dilution, or other methods. 


\section{Contents}

Summary $\ldots \ldots \ldots \ldots \ldots \ldots \ldots \ldots \ldots \ldots \ldots \ldots \ldots \ldots \ldots \ldots \ldots$ iii

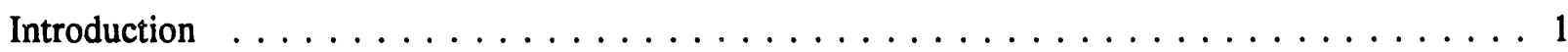

A Summary of Information from Tank $101-S Y \ldots \ldots \ldots \ldots \ldots \ldots$

Waste Simulant Compositions $\ldots \ldots \ldots \ldots \ldots \ldots \ldots \ldots \ldots \ldots \ldots$

Physical Properties of Waste Simulants $\ldots \ldots \ldots \ldots \ldots \ldots \ldots \ldots$

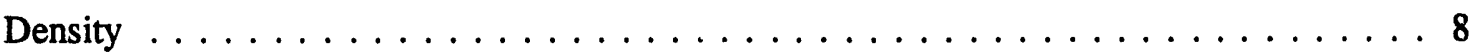

Solids Content and Settling Rates $\ldots \ldots \ldots \ldots \ldots \ldots \ldots$

Rheological Properties $\ldots \ldots \ldots \ldots \ldots \ldots \ldots \ldots \ldots$

Heat Capacity and Thermal Conductivity $\ldots \ldots \ldots \ldots \ldots \ldots$

Gns Generation in Simulated Wastes $\ldots \ldots \ldots \ldots \ldots \ldots \ldots \ldots \ldots \ldots$

Relation of Nitrous Oxide and Hydrogen Production $\ldots \ldots \ldots \ldots \ldots$

Synergism Between Radiolytic and Thermal Processes . . . . . . . . . . . . . 12

Autogenous Hydrothermal Oxidation of Organic Waste Components $\ldots \ldots \ldots \ldots$

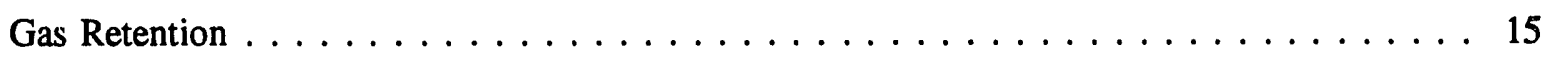

Nitrous Oxide Solubility $\ldots \ldots \ldots \ldots \ldots \ldots \ldots \ldots \ldots$

Gas Bubble-Solid Particle Interactions $\ldots \ldots \ldots \ldots \ldots \ldots \ldots$

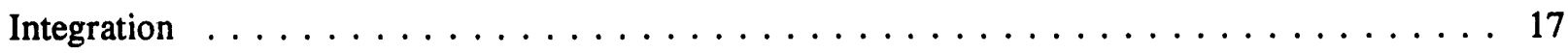

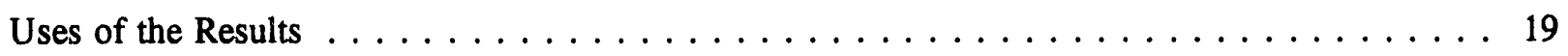

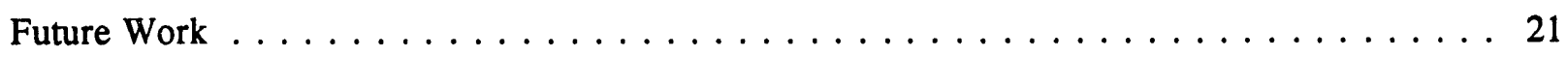

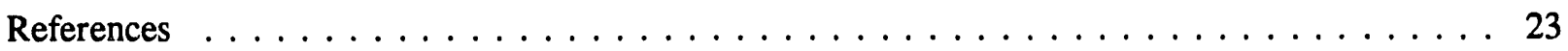


Appendix A - Calculation of an Activation Energy from Tank Data $\ldots \ldots \ldots \ldots \ldots$. . . . .

Appendix B - Definitions of Abbreviations for Organic Species $\ldots \ldots \ldots \ldots \ldots \ldots \ldots$ 


\section{Figures}

1 Surface Level Measurements from Tank 241-SY-101 using the RADAR Gauge

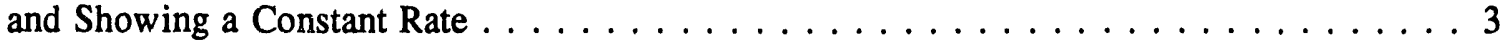

2 Adjusted Surface Level Measurements Showing the Constancy of the Rate of Growth Over the Past $3 \mathrm{Yr} \ldots \ldots \ldots \ldots \ldots \ldots \ldots \ldots$

\section{Tables}

1 Hydrogen Concentrations Measured in Tank 101-SY from Individual Samples

of the Vent Gas . . . . . . . . . . . . . . . . . . . . . . . . 4

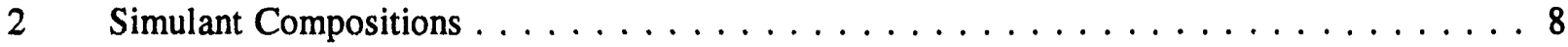

3 Products from the Decomposition of ${ }^{13} \mathrm{C}$-Labeled Organic Species . . . . . . . . . . 13

4 Nitrous Oxide Solubilities in Simulated Tank $101-S Y$ Wastes $\ldots \ldots \ldots \ldots \ldots$

5 Comparison of Gas Generation Data: Gas Composition Results . . . . . . . . . 18

6 Comparison of Gas Generation Results: Kinetic Results . . . . . . . . . . . . . 18 


\section{Introduction}

During the past two years, scientific studies have been carried out to determine the chemical mechanisms for gas generation in a waste tank located on the Hanford Site in Washington State. The waste contained in this tank consists of the residues of various processes used to separate plutonium from spent uranium metal fuel. In the particular case of Tank 241-SY-101 (referred to as Tank 101-SY in this report), gases are generated, both thermally and radiolytically, and partly retained such that the waste swells. Periodically, a portion of the retained gas is released. The gas consists of approximately equal volumes of hydrogen, nitrous oxide, and nitrogen. Because the concentration of hydrogen in the dome space of the tank can often exceed the lower flammability limit (4\%) during some of these releases, a potential safety problem exists that warrants investigation.

In this document, the results from the studies being carried out at Argonne National Laboratory, Georgia Institute of Technology, Pacific Northwest Laboratory, and Westinghouse Hanford Company are analyzed in an attempt to correlate the results from the different studies. There has been no attempt to provide a complete and thorough review of each of the studies; rather, summary information is taken from the publications and the references provided.

In this document, summary information obtained from the instruments in Tank 101-SY is discussed to lay the groundwork for a comparison with the data obtained in the laboratory. A discussion of the chemical properties of simulated wastes emphasizes the composition and the similarity to the aciual waste and includes results from the radiolysis experiments. This discussion is followed by a section on the physical properties of the simulated wastes. After these brief discussions of the laboratory results, an attempt is made tc integrate the results into a consistent understanding of the chemical mechanisms for the generation of the gases in Tank 101-SY. 


\section{A Summary of Information from Tank 101-SY}

Much of what is known about the data from Tank 101-SY has been summarized in a number of documents (Anantatmula 1992; Babad et al. 1992; Reynolds 1991; Ashby et al. 1992). Since those documents have been released, new information has been obtained. Data from the waste level measuring devices have not led to any new conclusions about the rate of gas generation. Johnson (1992) suggested that the data between December 1991 and April 1992 indicate the waste in the tank is cooling and the rate of generation has decreased from a nominal $2.5 \mathrm{~mm} / \mathrm{d}(0.1 \mathrm{in} . / \mathrm{d})$ to $1.8 \mathrm{~mm} / \mathrm{d}$ $(0.07 \mathrm{in} . / \mathrm{d})$. These data have been reanalyzed using a least squares analysis of the linear portions of the data to show that the rate was $2.3 \pm 0.1 \mathrm{~mm} / \mathrm{d}(0.090 \pm 0.004 \mathrm{in} . / \mathrm{d})$ (Figure 1) and has been constant over at least the last $3 \mathrm{yr}$ (Figure 2). ${ }^{\text {(a) }}$ The data suggest that there was a small release of

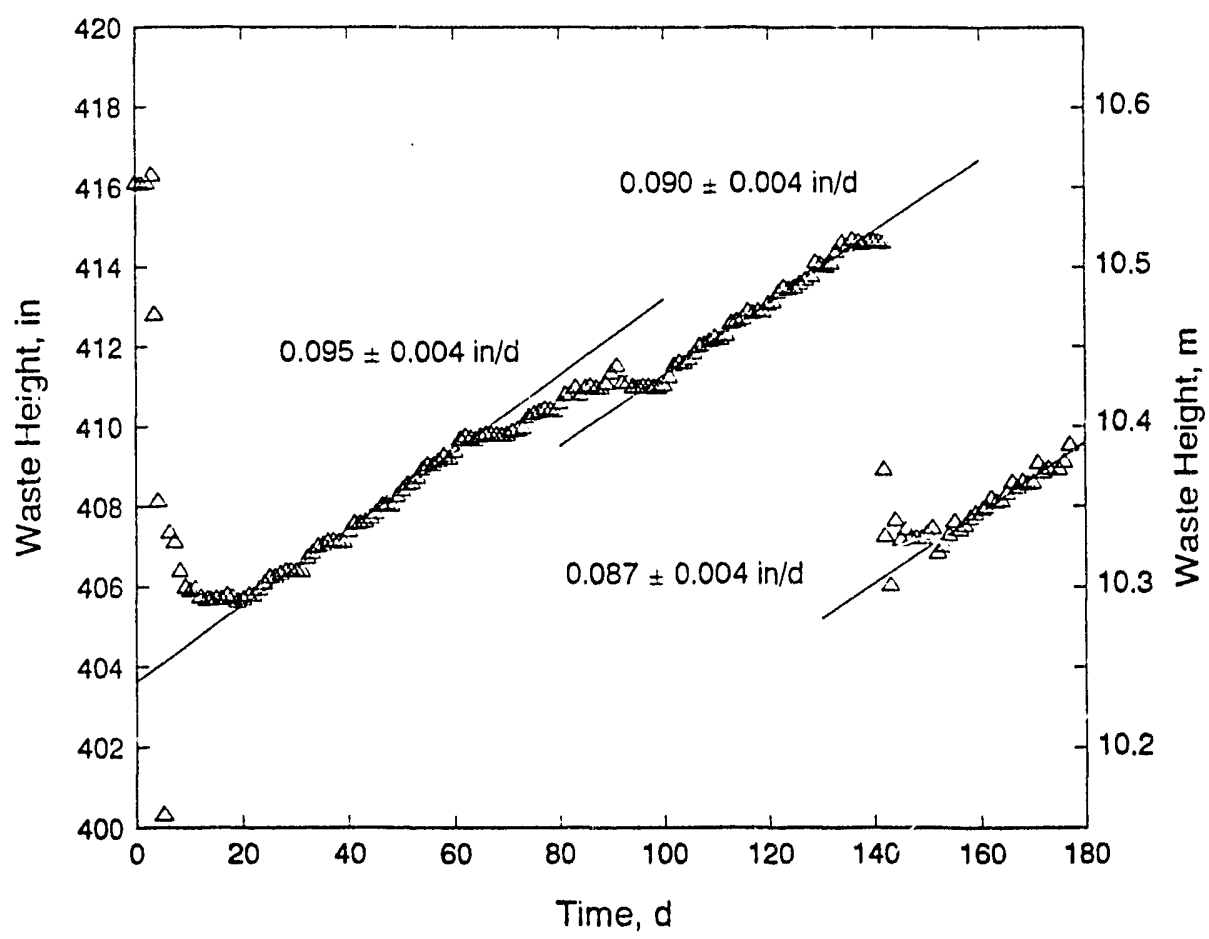

Figure 1. Surface Level Measurements from Tank 241-SY-101 using the RADAR Gauge and Showing a Constant Rate (Day $0=$ December 4, 1991)

(a) The rate is lower than the rates shown in Figure 1 because of an artifact of the data reduction. "Relative waste height" was obtained by adding the level changes due to gas release events to the subsequent level data. Not all of the data are shown to improve clarity. 


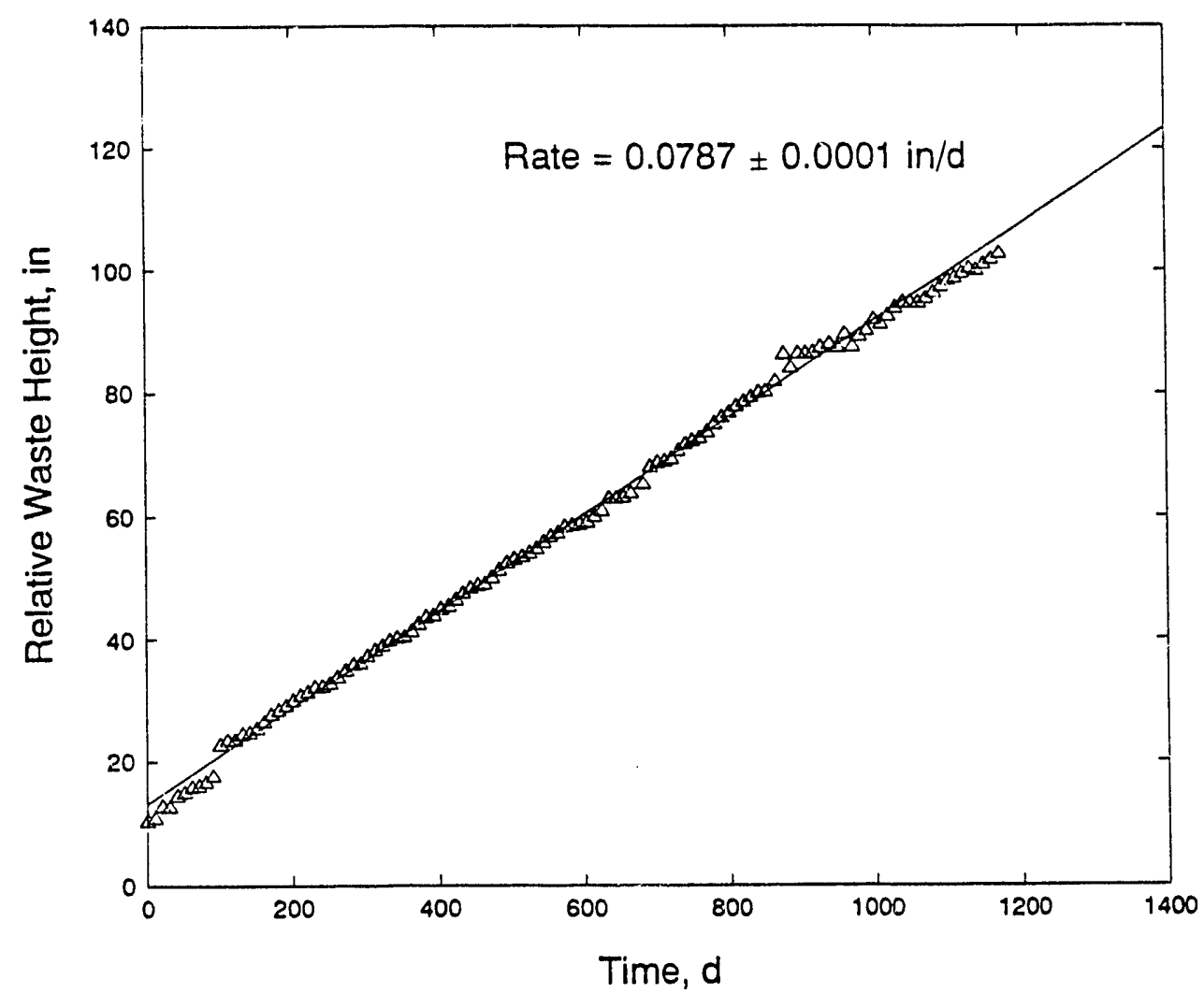

Figure 2. Adjusted Surface Level Measurements Showing the Constancy of the Rate of Growth Over the Past $3 \mathrm{Yr}$

gas about February 1992, such that the waste height did not change. Coincidentally, $\mathrm{H}_{2}$ concentrations measured during that same period showed an increase (Table 1). Unfortunately, the data set is not sufficiently complete to substantiate this conclusion.

Analyses of the level rise in the tank have given rise to the interpretation that the gas in the nonconvecting layer is trapped and not released to the layer above nor to the vent space, while the gas that is generated in the convecting layer is continuously released. For this mechanism it is assumed that the gas generation rate in the two layers is equal, but the gas in the convecting layer is released. Using these assumptions and a ventilation rate of $0.11 \mathrm{~m}^{3} / \mathrm{g}(600 \mathrm{cfm})$, the concentration of hydrogen in the vent space or vent header should be about $45 \mathrm{ppm}$. Recent values for the concentration of hydrogen in the vent header show the gas concentrations to be between $18 \mathrm{ppm}$ and $100 \mathrm{ppm}$ with a mean of $39 \mathrm{ppm}$. These data were obtained with a metal oxide semiconductor detector that is not part of an analytical instrument and has only a limited calibration. However, it is not expected that the measured values are incorrect by more than a factor of two. Thus, the existing data are consistent with the interpretation that has been generally accepted for the last year or so: gases are uniformly generated in the tank, released continuously from the convecting layer, and stored in the 
Table 1. Hydrogen Concentrations Measured in Tank 101-SY from Individual Samples of the Vent Gas

\begin{tabular}{lc}
\multicolumn{1}{c}{ Date } & Concentration, pp \\
\hline January 31, 1992 & 37,36 \\
March 3, 1992 & $104,92,114$ \\
March 5, 1992 & $63,60,68$
\end{tabular}

nonconvecting layer. Any measurable release of gases from the nonconvecting layer result in a corresponding decrease in the waste level or a decrease in the rate of level increase.

During the release of gases from Tank 101-SY in March 1992, the temperatures measured as a function of depth using a single set of thermocouples in the tank did not fluctuate as observed in previous gas release events. In previous events, the temperature as recorded using the fourth thermocouple from the bottom of the tank increased to about $57^{\circ} \mathrm{C}\left(134^{\circ} \mathrm{F}\right)$. In the event in question, the temperature increased to $52^{\circ} \mathrm{C}\left(125^{\circ} \mathrm{F}\right)$ at the time the gases were released. However, after the release, the temperature as measured at the fourteenth thermocouple from the bottom of the tank reached $55^{\circ} \mathrm{C}\left(131^{\circ} \mathrm{F}\right)$. This strongly suggests that, as hypothesized by Allemann (1992), the waste consists of "gobs" of material that reach neutral buoyancy at different times. Thus, while insufficient gas had been generated in the portion of waste nearby the thermocouple tree, at some other position the waste had become neutrally buoyant from the generated gases and, presumably, hotter. This result does not mean that the gas generation rate is different in different parts of the waste, but that the starting point toward neutral buoyancy depends on the history of that portion of the waste.

With respect to the cooling reported by Johnson (1992), there are some confounding data that call this interpretation into question. In the temperature data there are times when the temperature of the entire tank decreased by $0.5^{\circ} \mathrm{C}\left(1^{\circ} \mathrm{F}\right)$ in 1 to $2 \mathrm{~h}$. Since this rapid change in temperature is impossible for the large mass in the tank, the temperature data become suspect. Recently, however, the temperature measurement system, including the thermocouples, connecting lines, and data logger, has been checked and found to be within calibration. Thus, these anomalous readings may be due to the mixing of data from two sources and need to be checked. The original readings should not be discarded, however, because information about the physical mechanism can certainly be gleaned from the data.

Assuming for the moment that the waste in the tank is cooling at $1.5^{\circ} \mathrm{C} / \mathrm{yr}\left(3^{\circ} \mathrm{F} / \mathrm{yr}\right)$ (Johnson 1992) but that the error in the measurement of the rate masks any changes in the rate, one can calculate a maximum activation energy for the process by which gases are being generated in the waste. This activation energy can then be compared with typical activation energies to see if the observed rate and the suspected cooling trend make any sense. Instead of using the cooling rate of the waste, however, it is possible to consider the changes in the rate between gas release events for which there are more data. As shown in Figure 1, the data appear to be linear over much of the time 
cycle between events and in no case does the rate appear to increase. The error in the rate calculated from the data in Figure 1 is less than $5 \%$. This means that the ratio of the rate at the beginning of the 100-day cycle $\left(R_{1}\right)$ and the rate at the end of the cycle $\left(R_{2}\right)$ is $R_{2} / R_{1}=1.05$ and the temperature increased about $6 \mathrm{~K}\left(10^{\circ} \mathrm{F}\right)$. This is consistent with an activation energy for the rate limiting step in the gas generation mechanism of about $7 \mathrm{~kJ} / \mathrm{mol}(2 \mathrm{kcal} / \mathrm{mol})$ [see Appendix A for the details of this calculation]. A similarly low activation energy would be calculated using the cooling rate determined by Johnson (1992). This is a very low activation energy and would not be expected to be the result of a chemical process.

Activation energies have been measured in the laboratory at $80 \mathrm{~kJ} / \mathrm{mol}$ to $100 \mathrm{~kJ} / \mathrm{mol}$ (Ashby in Strachan 1991; Delegard 1980). However, if the activation energy for the rate limiting step in the generation of gases in the tank was $100 \mathrm{~kJ} / \mathrm{mol}$, then during the 100 days between events, the rate at the end of the period and just before a gas release event would be expected to be about 1.4 of the rate at the beginning of the $100-\mathrm{d}$ period. This calculation is based on a $3^{\circ} \mathrm{C}$ increase in the temperature at thermocouple \#4. If the temperature rise is greater, then the ratio of the rates would have to be greater than 1.4 to be consistent with an activation energy of $100 \mathrm{~kJ} / \mathrm{mol}$.

Alternatively, the observed rate could have an activation energy of $100 \mathrm{~kJ} / \mathrm{mol}$ if the mean temperature inciease was much less than that observed in the tank at the position of the thermocouples. The tank is about $23 \mathrm{~m}$ in dianieter and there is one thermocouple tree. There could be temperature inhomogeneiriss in the nonconvection layer that some of the time are not recorded using the single temperature medsurement source. Ev,n in the case where temperature inhomogeneities are indicated by the thermal response of the other thermocouples in the tree, temperatures in the nonconvecting layer increase by several degrees celsius. To address the question of the mean temperature increase, one can assume that the activation energy is $100 \mathrm{~kJ} / \mathrm{mol}$ and calculate how much the temperature would have to change for the rate to stay the same within experimental error. The results from this calculation indicate that if the ratio of the rates was 1.1 , the temperature increase would have to be about $1^{\circ} \mathrm{C}$; at a ratio of 1.05 , the change would be about $0.4^{\circ} \mathrm{C}$. These small temperature changes are simply not observed in the tank. It is thus possible to rule out an activation energy for the rate controlling step being higher than about $20 \mathrm{~kJ} / \mathrm{mol}$.

Diffusion could be the rate controlling mechanism and is consistent with the calculated activation energies based on the data from the level rise and temperature increases between each gas release event. The temperature dependence of the diffusion coefficient in fluids is related to the fluid viscosity. Typical Newtonian fluids have viscosities that exhibit Arrhenius behavior with activation energies in the range of a few kilogoules per mole to a few tens-of-kologoules per mole. Thus, diffusion of some reactive species over a short distance could be the rate limiting step in the mechanism for gas generation from the waste in Tank 241-SY-101, but other mechanisms might also yield the same low activation energies.

Radiolytic reactions or activation could also lead to species with reaction rates having low temperature dependence. The thermal gas generation rate in simulated waste solutions has been found to increase dramatically when the solution has been preirradiated (see Meisel in Strachan 1992b). This implies that a very reactive intermediate species is generated during radiolysis. Although the 
effect of the radiolysis is expected to have a low activation energy, i.e., have little temperature sensitivity, radiolysis is not expected to be the rate limiting step in the processes that yield gas in these solutions. Radiolysis of water does not appear to yield significant amounts of gas from the waste.

\section{Waste Simulant Compositions}

Several simulant compositions have been devised for use in laboratory studies in the place of actual waste from Tank 101-SY. The purpose of each of the simulant recipes was not necessarily to precisely reproduce the composition of the actual waste. Rather, the simulants were designed to aid in the conduction and interpretation of laboratory experiments aimed at determining chemical kinetics and mechanisms responsible for gas generation and retention in the wastes. Simulant compositions currently being used are given in Table 2 (weight percent and approximate molarity). Each composition has been given an alphanumeric code as an identifier.

Two simulant compositions form a slurry at tank temperatures. Simulant SY1-SIM-91A contains the principal inorganic constituents of the actual waste in addition to 0.3 molar organic complexants. This simulant composition was defined by D. L. Herting (WHC) and has been known as the "final word" recipe (Strachan 1992b). Simulant SY1-SIM-92A more closely represents the composition of the wastes in Tank 101-SY. In addition to the principal inorganic components, this simulant contains minor components found in actual wastes, including transition metals, chloride, fluoride, sulfate, and phosphate ions. The composition of this simulant was based on is weighted average of analyses of actual waste core samples obtained during Window " $C$ " (Herting et al. 1992).

Two simulant compositions, SY1-SIM-91B (Strachan 1992b) and SY1-SIM-91C (shown as Solution $P$ in Meisel et al. 1991), have been used in laboratory studies where homogeneous solutions were required. Simulant SY1-SIM-91B contains the principal inorganic components found in SY1-SIM$91 \mathrm{~A}$, but at $70 \%$ of the concentration of the latter. The hydroxide content of this simulant was boosted to prevent precipitation of aluminum hydroxide, however. Simulant SY1-SIM-91C differs from SY1-SIM-91B in that sodium carbonate is absent from the former and the concentration of sodium aluminate is substantially reduced. Homogeneous solutions are necessary to simplify interpretation of chemical kinetics studies performed in the laboratory.

While inorganic waste constituents of actual wastes are reasonably well-reflected in the compositions of the simulants listed in Table 2, organic constituents are not. One obvious reason is that the majority of organic constituents of the actual wastes have yet to be defined. Simulated wastes provide the flexibility of substituting known or anticipated organic components to determine chemical degradation mechanisms. Such mechanistic investigations would not be possible using actual wastes. 
Table 2. Simulant Compositions

\begin{tabular}{|c|c|c|c|c|c|c|}
\hline \multirow[b]{2}{*}{ Component } & \multicolumn{2}{|c|}{ SY1-SIM-91A } & \multicolumn{2}{|c|}{ SY1-SIM-91B } & \multicolumn{2}{|c|}{ SY1-SIM-92A } \\
\hline & WT\% & $\underline{\mathbf{M}}$ & WT\% & $\mathbf{M}$ & WT\% & $\mathbf{M}$ \\
\hline $\mathrm{NaOH}$ & 7.3 & 2.3 & 6.3 & 2.00 & 6.3 & 2.5 \\
\hline $\mathrm{NaAlO}_{2}$ & 11.8 & 2.2 & 8.3 & 1.54 & 10.5 & 2.1 \\
\hline $\mathrm{NaNO}_{3}$ & 20.0 & 3.7 & 14.0 & 2.59 & 12.0 & 2.2 \\
\hline $\mathrm{NaNO}_{2}$ & 14.6 & 3.2 & 10.2 & 2.24 & 17.5 & 4.0 \\
\hline $\mathrm{Na}_{2} \mathrm{CO}_{3}$ & 4.2 & 0.6 & 2.9 & 0.42 & 2.7 & 0.4 \\
\hline Organic & 2.4 & 0.3 & 1.7 & 0.21 & & -- \\
\hline $\mathrm{Na}_{4}$ EDTA & -- & -- & -- & - & 1.6 & 0.066 \\
\hline $\mathrm{Na}_{4} \mathrm{HEDTA}$ & -- & -- & -- & - & 3.3 & 0.14 \\
\hline $\mathrm{NaCl}$ & $\approx$ & -- & -- & - & 2.0 & 0.53 \\
\hline $\mathrm{Na}_{3} \mathrm{PO}_{4}$ & -- & -- & -- & -- & 4.4 & 0.18 \\
\hline $\mathrm{NaF}$ & -- & -- & -- & -- & 0.27 & 0.10 \\
\hline $\mathrm{Cr}\left(\mathrm{NO}_{3}\right)_{3}$ & -- & -- & -- & -- & 2.7 & 0.11 \\
\hline $\mathrm{Cu}\left(\mathrm{NO}_{3}\right)_{2}$ & -- & - & - & -- & 0.0026 & 0.00021 \\
\hline $\mathrm{Fe}\left(\mathrm{NO}_{3}\right)_{3}$ & -- & -- & -- & - & 0.087 & 0.0074 \\
\hline
\end{tabular}

\section{Physical Properties of Waste Simulants}

Densities, solids content, settling rates, rheological properties, heat capacities, and thermal conductivities of waste simulants have been evaluated in laboratory tests using waste simulants. Such data are needed to model gas retention and release phenomena in Tank 101-SY as well as to predict how the actual waste might behave when heated or diluted. Where possible, comparisons between physical properties of actual wastes and simulants have been made.

\section{Density}

Densities for settled solids and supernatant liquid from the waste simulant SY1-SIM-92A were measured as a function of temperature (Bryan and Pederson in Schulz and Strachan 1992). Supernate densities ranged from 1.4 to $1.5 \mathrm{~g} / \mathrm{mL}$ in the temperature range 25 to $80^{\circ} \mathrm{C}$, with no clear trend as a function of temperature within error bounds. Similar behavior has been found for segments of actual waste from the convecting layer of Tank 101-SY. Settled solids densities were typically 1.7 to $1.8 \mathrm{~g} / \mathrm{mL}$, again in reasonably good agreement with certain segments of the actual wastes.

Small increases in supernatant liquid densities with increased temperature were found in carefully controlled laboratory experiments where the supernate was heated in the presence of excess 
solids. This behavior was attributed to partial dissolution of those solids (Pederson and Bryan in Schulz and Strachan 1992). Supernate densities for the simulant SY1-SIM-91A increased from $1.44 \pm 0.02 \mathrm{~g} / \mathrm{mL}$ at $40^{\circ} \mathrm{C}$ to a maximum of $1.52 \pm 0.02 \mathrm{~g} / \mathrm{mL}$ at $85^{\circ} \mathrm{C}$. From these results, heating waste at the bottom of the cank would not be expected to be a viable means of inducing circulation within the wastes. Rather, waste layers would tend to be stabilized by heating. However, since it is believed that gas bubbles adhere to the solids that have slightly hydrophobic surfaces, dissolution of solids as a result of heating would release the adsorbed gas.

\section{Solids Content and Settling Rates}

The fraction of solids present in the waste simulant SY1-SIM-92A as well as rates of solids settling have been measured as a function of temperature and dilution with sodium hydroxide solutions (Bryan and Pederson in Schulz and Strachan 1992b). Weight percents and volume percents of solids present were found to decrease substantially as waste simulants were diluted with 2 molar sodium hydroxide solution. This behavior was expected and desired; with fewer solids present, the extent of gas retention in the wastes should be lessened. No clear trend in the solids content as a function of temperature was found. When the simulants were diluted with 0.1 molar sodium hydroxide, the solids content did not diminish as before. Precipitation of aluminum hydroxide may have offset any increased dissolution of sodium nitrate and sodium nitrite under such conditions. It is known that aluminum hydroxide becomes the preferred phase for base concentrations smaller than approximately 1 molar, whuse solubility decreases rapidly with decreased base content; sodium aluminatc; is the preferred phase for base concentrations greater than that value (Barney 1976). In these experiments, however, the solids were not directly analyzed, so it is uncertain whether the increase in solids content was due to the precipitation of aluminum-containing solids when the diluent was 0.1 molar sodium hydroxide.

Solids were found to settle more quickly as the temperature was increased and as the waste became more dilute (Bryan, Pederson, and Scheele 1992). Temperature had a much greater effect on solids settling velocities for diluted simulants than undiluted compositions. The cause for such behavior is not understood at present. These trends suggest that a specific phase(s) strongly affects settling behavior and is preferentially dissolved in diluted simulants. Sodium nitrite, which can crystallize in the form of dendrites with a high surface area to volume ratio, might be playing a controlling role. Sodium nitrite dendrites have been suggested as the critical component that determines the shear strength of the nonconvecting layer in actual Tank 101-SY wastes (Alleman 1992).

\section{Rheological Properties}

Shear strengths for the waste simulant composition SY1-SIM-92A were determined as a function of temperature following the same procedure used to evaluate actual waste cores (Bryan and Pederson in Strachan 19926). Settled solids from simulated wastes typically gave shear strengths of 1 to $2 \mathrm{kPa}$ (10 000-20 000 dynes $\left./ \mathrm{cm}^{2}\right)$ at room temperature and even lower values at elevated temperatures. These results compare favorably with actual waste segments taken from within or near the convecting 
layer, but are considerably smaller than values obtained for actual crust samples (as high as $25 \mathrm{kPa}$ (250 000 dynes $/ \mathrm{cm}^{2}$ ) at ambient temperatures) or for nonconvecting layer samples (as high as $12 \mathrm{kPa}$ [120 000 dynes $\left.\left./ \mathrm{cm}^{2}\right]\right)$.

It is not clear whether or not the methods used to measure shear strength yielc results that accurately represent the properties of the wastes. Results reported above were derived from the resistance to continuous rotation of vanes inserted into the wastes. Alternately, a paddle-like probe was placed into simulated waste samples heated to approximately $80^{\circ} \mathrm{C}$. The waste was allowed to cool to tank temperatures (ca $55^{\circ} \mathrm{C}$ ) and solids were allowed to crystallize. Shear strengths were determined from the initial force required to move the paddle rather than the resistance to contir: s rotation. Initial shear strengths were considerably larger than those derived from continuous sit ing. Extensive fracture of dendritic sodium nitrite grains initially present in the waste samples may partially account for the difference between initial and later shear strength determinations. Similarly, it may be that the fracture of dendritic sodiu in ritrite grains is the controlling factor in determining when periodic releases of flammable gases occur from Tank 101-SY.

\section{Heat Capacity and Thermal Conductivity}

Average heat capacities and thermal conductivities have been determined for simulated wastes as a function of temperature. Such data are needed to model how he tank waste might respond to localized heat loads. Insight on how actual wastes might respond can be gained using simulated wastes; refinement of experimental methods that can be used to evaluate waste cores in a hot cell environment is also a benefit.

Average heat capacities for SY1-SIM-92A simulated wastes have been measured as a function of temperature. Three separate segments of the waste simulant SY1-SIM-92A were evaluated: supernatant liquid, settled solids, and an integral sample containing both supernate and settled solids. These gave average heat capacities in the temperature range 55 to $80^{\circ} \mathrm{C}$ of $0.62 \pm 0.06,0.53 \pm 0.05$, and $0.40 \pm 0.04$ calories $/ g-k$, respectively. The influence of exothermic dissolution processes is believed responsible for the relatively low value obtained for the integral sample. Clearly, a weighted average of heat capacities of tank waste cores might not accurately reflect the properties of the whole.

Using the line source method (Tye 1969), the thermal conductivity of settled solids in simulated wastes (SY -SIM-92A) was determined. The settled solids consisted of a loosely packed layer above a much smaller layer of relatively densely packed solids. The layer containing loosely packed solids gave a thermal conductivity of $0.641 \mathrm{~W} /(\mathrm{m} \cdot \mathrm{K})$ with a standard deviation of $0.043 \mathrm{~W} /(\mathrm{m} \cdot \mathrm{K})$, based on eighteen separate runs over the temperature range 28 to $79^{\circ} \mathrm{C}$. There was no statistically significant variation in thermal conductivity over that temperature range. The thermal conductivity of densely packed bottom solids was $0.815 \mathrm{~W} /(\mathrm{m} \cdot \mathrm{K})$ with a standard deviation of $0.023 \mathrm{~W} /(\mathrm{m} \cdot \mathrm{K})$ for three runs performed at room temperature.

Thermal conductivities for simulated wastes reported above are within the range of values reported previously for various tank solids (Bouse 1975). Actual tank waste samples reported in that study gave thermal conductivity values from 0.151 to $1.848 \mathrm{~W} /(\mathrm{m} \cdot \mathrm{K})$, with values dependent on 
sample composition, moisture content, temperature, density, and other physical characteristics. Actuxil waste samples exhibited a much larger range of heterogeneity than occurred for simulated wasts samples, which could account for the much larger range of values for the actual waste segisents.

\section{Gas Generation in Simulated Wastes}

\section{Relation of Nitrous Oxide snd Fiydragen Production}

Perhaps one of the more significant findings of this past year is that nitrous oxide and hydrogen yields are not particularly coupled. Previously, the lack of agreement of nitrous oxide/hydrogen ratios found in simulated waste experiments and in gases vented from Tank 101-SY was believed to be a major discrepancy (Ashby et al. 1992) and cast some doubt on the value of testing using simulated wastes. More recent results have demonstrated that the nitrous oxide/hydrogen ratio is affected by a number of parameters. Among them are hydroxide, chloride, and transition metal concentrations and the organic species.

The effect of silicon dioxide on gas generation has been reported indirectly by Herting (in Strachan 1992a; Delegard 1980). It was recognized that aluminate ions needed to be present in solution for the chemical generation of gas (Delegard 1980; Herting in Strachan 1992a). Performing experiments in glass equipment at elevated temperatures caused precipitation of cancrinite $\left[\mathrm{Na}_{6} \mathrm{Ca}_{2}\left(\mathrm{CO}_{3}\right)\left(\mathrm{AlSiO}_{4}\right)_{6}\right.$ - ideal stoichiometry] and a concomitant decrease in the aluminate and hydroxide concentrations. Recently, Ashby et al. (in Schulz and Strachan 1992) reported similar effects when glass portions of a Teflon -lined glass reaction vessel were exposed to the test solutions. Irreproduceable results were obtained from the experiments. In subsequent experiments using better test vessels into which glass beads were introduced, gas generation was substantially reduced.

The molar ratio of nitrous oxide to hydrogen has been shown to depend quite strongly on the concentration of hydroxide ion in the simulant (Bryan and Pederson in Schulz and Strachan 1992). Nitrous oxide/hydrogen ratios for simulated wastes containing either EDTA or HEDTA (see Appendix B for definitions of organic species abbreviations) varied from values less than 1 to more than 10 as a result of altering the hydroxide ion concentration from approximately 0.5 to 6.5 molar. For sodium citrate, nitrous oxide/hydrogen ratios varied from essentially zero to approximately 1 over the same hydroxide concentration range. Dilution of the waste simulants with 2 molar sodium hydroxide up to 30 volume percent also gave wide variations in gaseous product ratios (Bryan and Pederson in Strachan and Schulz 1992). Of course, other changes occur in the chemistry of the waste simulant when the hydroxide ion concentration is altered, most notably the concentration of sodium aluminate in solution (Barney 1976).

Gas generation from simulant compositions SY1-SIM-91A and SY1-SIM-92A containing varying concentrations of HEDTA were directly compared by Bryan (Bryan and Pederson in Schulz and Strachan 1992). The overall quantity of gases that were produced were similar for the two compositions, as were the yields of hydrogen. However, nitrous oxide and nitrogen concentrations were sub- 
stantially different. Simulant SY1-SIM-91A favored the production of nitrogen, while SY1-SIM-92A yielded larger quantities of nitrous oxide. The principal differences between the two waste simulants is that SY1-SIM-91A contains only the principal inorganic components present in Tank 101-SY, while SY1-SIM-92A additionally contains minor concentrations of transition metals, chloride, fluoride, sulphate, and phosphate ions. More recently, Bryan showed that variations in the chloride ion concentration had a significant impact on nitrous oxide/hydrogen ratios (Bryan, Pederson, and Scheele 1992). Ashby has reported that the rate of hydrogen production is accelerated in the presence of $\mathrm{Cu}(I I)$ (Ashby et al. in Schulz and Strachan 1992). Minor and trace waste component concentrations would thus appear to be important parameters to be examined in determining the kinetics and mechanisms of fiammable gas generation.

The identity of the organic constituent is perhaps the most important factor in determining the relative yields of nitrous oxide, hydrogen, and nitrogen in Tank 101-SY wastes. As reported previously (Ashby et al. 1992), nitrous oxide/hydrogen ratios in the range 5:1 to 20:1 were typical of a number of studies when HEDTA and EDTA were the principal organic constituents of the simulated waste. Other organic compounds have yielded much different nitrous oxide/hydrogen ratios. For sodium citrate, that ratio ranged from 0 to 1.1, depending on the base concentration (Bryan and Pederson in Schulz and Strachan 1992). Sodium glycolate also produced principally hydrogen (Herting in Strachan 1992a and in Schulz and Strachan 1992). Formaldehyde favors the formation of hydrogen by nearly two orders of magnitude (Meisel et al. in Strachan 1992b). Ashby has examined a wide range of model compounds in mechanistic studies of organic degradation reactions, many of which yielded hydrogen as the principal degradation product (Ashby et al. in Schulz and Strachan 1992).

Although much of the mechanism for the breakdown of the water soluble organic species is becoming clear, much work remains to be done. One of the key tools in elucidating the chemical reaction path has been the use of isotopically enriched chemical species. Both ${ }^{13} \mathrm{C}$ - and ${ }^{15} \mathrm{~N}$-labeled species have been used with great success. Results from studies with ${ }^{13} \mathrm{C}$-labeled HEDTA, where the carbons on the hydroxyethylene group and, separately, the carbons on the carboxyethylene groups have been labeled with ${ }^{13} \mathrm{C}$, indicate that attack of the HEDTA molecule occurs at the amine group causing displacement of electrons and, ultimately, destabilization of the molecule. Complete details of this mechanism are given by Ashby (in Strachan 1992a,b). The main products from the ${ }^{13} \mathrm{C}$-labeled organics are shown in Table 3.

Results from the ${ }^{15} \mathrm{~N}$-labeling studies indicate that the $\mathrm{NO}_{2}^{-}$is the source for the nitrogen-bearing gases $\mathrm{N}_{2} \mathrm{O}, \mathrm{N}_{2}$, and $\mathrm{NH}_{3}$ (Ashby in Strachan 1992a,b; Schulz and Strachan 1992). These results were also confirmed by Meisel at Argonne National Laboratory (Meisel in Strachan 1992b).

\section{Synergism Between Radiolytic and Thermal Processes}

An interesting synergism between radiolytic and thermally driven degradation mechanisms has been recently demonstrated by Meisel (Strachan and Schulz 1992). In his experiments, pre-irradiation of waste simulants resulted in an enhancement in the thermal generation of hydrogen and nitrous oxide. Homogeneous (SY1-SIM-92C) simulant solutions containing either EDTA, HEDTA, or 
Table 3. Products from the Decomposition of ${ }^{13} \mathrm{C}$-Labeled Organic Species. (See Appendix A for the abbreviations for the chemical species given below.)

\begin{tabular}{|c|c|}
\hline Component & 13 \\
\hline HEDTA $^{(a)}$ & $\mathrm{CH}_{2} \mathrm{O}, \mathrm{C}_{2} \mathrm{O}_{4}^{2-}$, \\
\hline HEDTA $^{(b)}$ & $\begin{array}{l}\mathrm{HCO}_{2}^{-}, \mathrm{CO}_{2}, \mathrm{C} \\
\text { s-EDDA or } \mathrm{ED}\end{array}$ \\
\hline Glycolate & $\mathrm{C}_{2} \mathrm{O}_{4}^{2-}$ \\
\hline
\end{tabular}

citrate were irradiated to a total dose of approximately $40 \mathrm{Mrad}$. Less than $1 \%$ of the parent compound was degraded by this treatment. After standing from 5 to 40 days at room temperature, these solutions were heated to $60^{\circ} \mathrm{C}$ and the quantity of gaseous products assessed. Pre-irradiation increased the rate of formation of hydrogen and nitrous oxide by approximately a factor of ten. Hydrogen yields increased in the order citrate < HEDTA < EDTA, whereas nitrous oxide yield increased in the order citrate < EDTA < HEDTA. In addition, the quantity of hydrogen that could be produced increased wit! $\mathrm{L}: \mathrm{increase}$ in total dose up to approximately $20 \mathrm{Mrad}$, and then decreased with further irradis: $u$... It would appear that pre-irradiation leads to the formation of some quite reactive but unknown degradation product that may be further degraded thermally.

Radiolytic hydrogen production in pre-irradiated simulants in the form of a slurry was found to be approximately double that in otherwise identical homogeneous waste solutions that had been similarly treated. In contrast, nitrous oxide yields were not affected. It would appear that the slurry particles are able to catalyze the formation of hydrogen, although the mechanism is not known.

Pre-irradiation was effective in activating simulated waste samples to produce hydrogen, even when those samples had first been digested at $120^{\circ} \mathrm{C}$ (Meisel et al. in Strachan 1992a,b; Schulz and Strachan 1992). Prior to pre-irradiation, no hydrogen could be thermally generated from SY1-SIM91B solutions originally containing $0.21 \mathrm{M}$ HEDTA that had been digested for nearly three weeks at $120^{\circ} \mathrm{C}$. Organic analyses showed that none of the parent compound remained after this treatment. Exposure of this sample to $16 \mathrm{Mrad}$ of irradiation led to the activation of this sample, and both hydrogen and nitrous oxide were formed. It would appear that different intermediates are formed in the thermal degradation of the complexants than by radiolytic processes. Intermediates produced thermally can still be activated by radiation, and further degrade to yield hydrogen and nitrous oxide.

\section{Autogenous Hydrothermal Oxidation of Organic Waste Components}

Heating of the wastes in Tank 101-SY in the temperature range 200 to $350^{\circ} \mathrm{C}$ (below the critical point of water) is one means under consideration for decomposing organic components of the waste. 
If returned to the tank following this treatment, it is expected that these wastes will generate little, if any, additional flammable gases. The term "autogenous" is used to indicate that no oxidants are added to the waste simulant. Rather, nitrite and nitrate ions, both present in the wastes in high concentrations, serve as oxidants. To test the extent of degradation that might be expected in actual wastes, batch and continuous flow tests were performed using simulated wastes containing a single organic constituent (Pederson and Bryan in Schulz and Strachan 1992).

Ammonia was one of the principal degradation products. Organic nitrogen was essentially stoichiometrically converted to ammonia within $1 \mathrm{~h}$ in the temperature range 200 to $250^{\circ} \mathrm{C}$. Ammonia was also produced in batch reactions in which no organic nitrogen was present, such as in the cases of sodium citrate and sodium glycolate, although the quantity was approximately a factor of ten less than found for EDTA, HEDTA, and glycine. Control samples containing no organic components produced detectable but considerably smaller ammonia concentrations. Ammonia can thus be produced from inorganic nitrogen, but the yield is enhanced by the presence of organic carbon. Results from Ashby suggest that most of the ammonia comes from the organic nitrogen (Schulz and Strachan 1992).

Depending on temperature and residence times, total organic carbon content and energy content of the simulated wastes were lowered by autogenous oxidation. Total organic carbon concentrations were reduced anywhere from zero to approximately half of the original quantity as a result of heating in the range of 200 to $250^{\circ} \mathrm{C}$ for $1 \mathrm{~h}$, depending on the identity of the organic constituent. In tests using a continuous flow reactor, TOC was lowered by a factor of 30 following treatment at $350^{\circ} \mathrm{C}$ for 5 minutes. Reductions in total organic carbon reflected complete conversion to carbonate, "hereas partially oxidized products such as oxalate were included in total organic carbon results. Oxalate was the predominant form of organic carbon remaining following hydrothermal oxidation tests. Quantities of oxalate that can be sent to grout may be regulated; this issue may limit the acceptability of this approach to destroy organics in Hanford waste tanks.

Other changes in simulant chemistry as a result of heating to 200 to $250^{\circ} \mathrm{C}$ include consumption of hydroxide. Hydroxide ions were consumed in the batch tests, lowering the concentration by as much as 1 equivalent $/ \mathrm{kg}$ simulant that initially contained 0.2 moles $/ \mathrm{kg}$ of organic complexants such as EDTA and NTA. Lowering of the base content may substantially reduce the solubility of sodium aluminate in the wastes. Barney (1976) has shown that aluminum hydroxide will precipitate rapidly as the hydroxide concentration is reduced below perhaps 1 mole $/ \mathrm{kg}$, whereas above that concentration, sodium aluminate is the dominant form. Babad (Bryan and Pederson in Schulz and Strachan 1992) has concluded that additional base may be required to be added to the wastes prior to heat treatment for maximum efficiency and to prevent precipitation of aluminum hydroxide.

Gas generation tests were conducted for heat-treated waste stimulants (Bryan and Pederson in Schulz and Strachan 1992). Rates of flammable gas production were reduced in some cases to below detection limits, indicating that this approach may have significant value. Interpretation of the results may be somewhat complicated by the lowering of the base content and perhaps also the aluminate concentration in these samples as a result of heating. As shown by Delegard (1980), rates are dependent on both the aluminate and hydroxide concentrations. 


\section{Gas Retention}

\section{Nitrous Oxide Solubility}

The solubility of product gases in Tank 101-SY are of interest for several reasons. Dissolution of the gases provides one means for retention of these pruducts in the waste slurry. Because gas solubilities generally decrease with increased temperature, waste heating could lead to the release of a portion of the dissolved gases. Different relative solubilities of product gases could also affect the stoichiometry of gases that are released during periodic turnover events. In distilled water, nitrous oxide is approximately 20 times more soluble than hydrogen (Young 1981). Gas solubilities are known to generally decrease as ionic strength is increased. Literature data are not available for wastes similar to those in Tank 101-SY, however.

Nitrous oxide solubilities were measured as a function of temperature and nitrous oxide partial pressure in the simulated waste composition SY1-SIM-92A (Bryan and Pederson in Schulz and Strachan 1992). In simulated wastes as in distilled water, quantities of nitrous oxide dissolved were directly proportional to the partial pressure of that gas, following Henry's Law. Nitrous oxide solubilities in simulated wastes were substantially lower than in deionized water or in concentrated sodium nitrate solutions, as given in Table 4 . The solubility of nitrous oxide at $25^{\circ} \mathrm{C}$ in distilled water is $1.04 \mathrm{~g} / \mathrm{kg}$ water-atm nitrous oxide (Young 1981), approximately 30 times higher than that determined in simulated wastes.

Given the relatively low magnitude of values given in the above table, and in consideration of laboratory observations that dissolution/exsolution processes are quite slow, it is unlikely that dissolved gases contribute substantially to the quantity released during periodic gas release events nor substantially alter the observed stoichiometry of gaseous products. Likewise, the quantity of gas expected to be exsoluted as a function of waste heating is inconsequential.

\section{Gas Bibble-Solid Particle Interactions}

Liquid densities, liquid surface tensions, and equilibrium solid/liquid contact angles were measured as a function of temperature and organic complexant concentration, to examine how wetting phenomena might affect gas retention in Tank 101-SY and how gas retention might be reduced or prevented (Bryan and Pederson in Strachan 1992a,b; and Schulz and Strachan 1992). The principal hypothesis being tested was that gases are retained in the wastes as bubbles that are attached to solid particles as a result of surface tension forces. By manipulation of wetting behavior, it may be possible to allow the gases produced in the wastes to be vented continuously rather than undergo buildup and release cycles.

The Young-Dupre' equation describes expected trends in wetting behavior as a function of the interfacial tensions between the solid, liquid, and gas phases:

$$
\cos \theta=\left[\sigma_{s V}-\sigma_{s L}\right] / \sigma_{L V}
$$


Table 4. Nitrous Oxide Solubilities in Simulated Tank 101-SY Wastes

$$
\text { Temperature, }{ }^{\circ} \mathrm{C} \quad \text { Solubility, } \mathrm{g} / \mathrm{kg} \text { waste } / \mathrm{atm} \mathrm{N}_{2} \underline{\mathrm{O}}
$$

$$
0.034 \pm 0.017
$$

The contact angle, $\theta$, is that measured between the solid and liquid phases. A value of $\theta=0^{\circ}$ is indicative of complete solids wetting and no tendency for gas bubbles to adhere to solids, while a value of $\theta=180^{\circ}$ is indicative of the absence of wetting and a large tendency for gas bubble adherence to solids. The terms $\sigma_{\mathrm{SV}}, \sigma_{\mathrm{SL}}$, and $\sigma_{\mathrm{LV}}$ refer to interfacial tensions at the solid/vapor, solid/ liquid, and liquid/vapor interfaces, respectively. The identity of the gas phase is probably not important, as the mass densities of most gases are similar and quite small.

The following conclusions were drawn: 1) Liquid surface tensions for simulated wastes are considerably higher than that for pure water because the concentrations of electrolytes are higher. In consideration of the Young-Dupre' equation, high values of the liquid surface tension decrease solids wetability and enhance gas bubble adhesion to solids. Surfactant addition may be a viable means to reduce the liquid surface tension, if a surfactant of appropriate chemical and radiation stability could be found. 2) Equilibrium contact angles, measured by trapping gas bubbles on the bottom side of a flat alumina substrate, were found to increase substantially with the concentration of organic complexants in the waste. Complexant idsorption is believed to lower the wetability of the solids, thereby enhancing the tendency for gas bubbles to be retained in the waste.

Gas bubbles have been found to be particularly difficult to remove from solid particles (Meisel et al. in Schulz and Strachan 1992). Gas bubbles could not be decoupled substantially from solid particles by evacuation, rapid stirring, or sparging. The only very effective method of freeing the trapped gas bubbles was to heat or dilute until essentially all of the solids were dissolved. These observations have important implications for mitigating periodic flammable gas releases from Tank 101-SY. Other than to significantly alter the surface tension of solids through addition of a surfactant (none are known that are stable under radiative and thermal conditions in the tank), there probably exist no methods that are capable of completely decoupling solids and gas bubbles in the wastes because the interaction energies are apparently too large. A more effective strategy might be to lower the yield strength of the nonconvecting layer by mixing, sonication, heating, dilution, or other methods. Lowering the yield strength of that layer night reduce the minimum buoyancy needed for segments of the nonconvecting layer to rise within the tank and release a portion of trapped flammable gases. Attempting to decouple solids and gas bubbles would probably not be fruitful. 


\section{Integration}

An effort was made to integrate the gas generation rates and gas compositions from the simulated waste studies with the data from the tank. These data are reported in Tables 5 and 6 . These data indicate that the variance in the gas composition and the generation rates are quite large - varying over about 2 orders of magnitude. It appears, however, that the ratio of hydrogen to nitrous oxide, while variable, is a sensitive function of the waste composition. The data on the effect of waste composition on the gas composition is just becoming available and should become more complete during the next fiscal year. Recent analyses of selected solutions indicate that much different products result from radiolysis experiments than from purely thermal experiments. It is uncertain at this time if the gas composition should be expected to be the same as in the tank. There are indications that the reactions that generate nitrous oxide are independent oi the reactions that generate hydrogen, but there are indications of the opposite as well.

Gas generation rates do not scale well with respect to an activation energy of $100 \mathrm{~kJ} / \mathrm{mol}$.

The values shown in parentheses are the values calculated assuming the reaction leading to gases is first order with an activation energy of $100 \mathrm{~kJ} / \mathrm{mol}$. Using a lower activation energy would yield some comparable values, but others would then be in error. Clearly, more work is needed in this area before a strong correlation between the laboratory data and the tank data is developed.

It is also clear that the rate limiting step in the mechanisms proposed by the Georgia Institute of Technology group has not yet been determined. As the products of the decomposition of HEDTA, EDTA, and glycolate are sorted out, it should become clear which of the reactions is the rate limiting reaction. This product sorting has not yet been done but should be given a high priority.

It is tempting to ascribe some of the observed differences to diffusion. Diffusion is consistent with the data obtained from the tank. If diffusion represents the rate limiting step, then the relative rates of generation will depend on the functional dependence of the diffusion coefficients on the viscosity of the liquid/slurry. Thus, hydrogen generation might be controlled by mass transport (diffusion) rather than by specific chemical reactions. Couple this effect to the difference between the conditions in laboratory experiments and in the tank, and it might be possible to understand why the two yield such different results. Unfortunately, definitive experiments have not yet been performed. Some of these experiments are planned for FY 1993. 
Table 5. Comparison of Gas Generation Data: Gas Composition Results. These data include all the experiments performed at the various institutions under all conditions.

Data from

Tank 101-SY
Laboratory Results

\begin{tabular}{|c|c|c|c|}
\hline ANL & GIT & PNL & WHC \\
\hline $6-60$ & $10-25$ & 3 & $40-80$ \\
\hline $94-40$ & $0.1-0.5$ & 63 & $1-40$ \\
\hline- & - & 34 & 20.40 \\
\hline $0.06-1.5$ & $0.004-0.04$ & 0.04 & $1-45$ \\
\hline
\end{tabular}

\section{Radiolytic $^{(a)}$}

$\begin{array}{lccc}\mathrm{H}_{2}(\%) & 36 & 17 & 20 / 40-60 \\ \mathrm{~N}_{2} \mathrm{O}(\%) & 28.5 & 76 & 63 / 1-20 \\ \mathrm{~N}_{2}(\%) & 27 & 7 & 16 / 1-40 \\ \mathrm{H}_{2}: \mathrm{N}_{2} \mathrm{O} & 1.3 & 0.2 & 0.3 / 0.1-0.5\end{array}$

(a) The data under "WHC" include results from core samples; first number is from SY1SIM-91A in tests run at PNL.

Table 6. Comparison of Gas Generation Results: Kinetic Results.

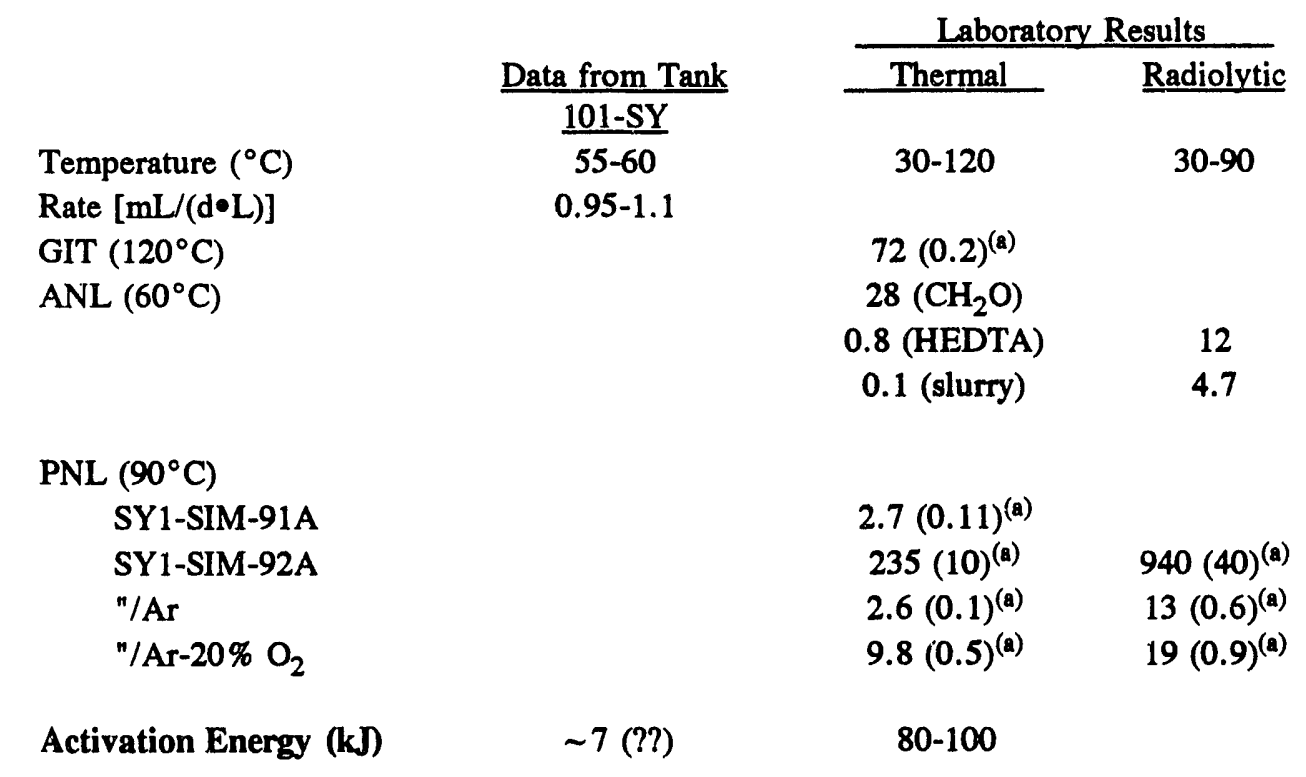

(a) Calculated rate at $60^{\circ} \mathrm{C}$ assuming $100 \mathrm{~kJ} / \mathrm{mol}(25 \mathrm{kcal} / \mathrm{mol})$ activation energy. 


\section{Uses of the Results}

The results from the studies discussed above have benefitted the Tank Safety Program in several ways. The results of the simulated waste studies were used in the safety analyses that enabled work to be performed in the tanks. Plans to mitigate the release of gases from Tank 241-SY-101 have also berefitted from the studies.

In 1990, the general feeling was that the gases were possibly held as a large bubble under the surface of the waste and that the waste was covered by a hard crust that might also be flammable. Although the composition of the crust was known, it was not known why the solids floated on a liquid with lower density. The results from the simulated waste studies indicated that the crust is sufficiently moist to prevent it from burning yet sufficiently permeable to allow gases to pass through. The presence of a permeable crust precluded the presence of a large gas bubble under the crust. It was also determined that the likely mechanism by which the crust formed was by bubble attachment to the solid particles in the waste. At some point, the bubble-solid entity would become sufficiently buoyant to rise to the surface and form a crust. This effect was observed in the laboratory.

Laboratory results also suggest that bubbles also form on the solids in the non-convecting portion of the waste in the tank. These entities are held by forces between solid particles and other forces within the gas-solid-liquid slurry. After sufficiently large volumes of gas are generated, buoyant forces become greater than the forces holding the material together. When this occurs, the gases rise to the surface and a portion of the gas is released. These forces were investigated in the laboratory.

From a knowledge of the forces and mechanism by which the gases in the tank are held, mitigation and remediation techniques have been suggested and the probability of success of these methods can be determined.

As discussed in the proceeding sections of this report, the mechanism by which the gases are generated is more fully understood. It is understood, for instance, that simply stopping the thermal generation of the gases will not stop the gas generation completely; radiolytic generation will continue, albeit the generation rate will be substantially reduced. From the studies of the chemical generation of the gases, it was determined that low molecular weight organics such as formate and oxalate should be analyzed. Analytical results suggest that a major portion of the total organic carbon in Tank 214-SY-101 is oxalate and formate. This knowledge reduces estimates of the hazard associated with the organic content because these organics represent a large degradation of the ene:gy associated with the parent organics that were assumed to be present in the waste when the safety analyses were performed.

It is anticipated that the results from the continuing work with simulated wastes will continue to provide answers to open questions concerning the waste in Tank 241-SY-101 and other tanks. 


\section{Future Work}

To complete the studies on the mechanism(s) of gas generation in simulated waste solutions, several key questions need to be addressed. Answers to some of these questions may be found by analyzing the existing data. A partial list of the questions that need to be answered follows:

- What is the rate limiting step in the suite of reactions that appear in the proposed reaction mechanism?

- What is the activation energy for the overall reaction and how does that relate to the apparently low activation energy exhibited by the reactions taking place in the tank?

- How does composition of the waste affect the gas generation rate and the ratio of the gases produced?

- What is the role of radiolysis in the overall mechanism of gas generation?

- What is the mechanism that leads to nitrosoiminodiacetate, which is the major organic component found in waste samples when the organic components are derivitized to form the esters?

- What is the mix of organic compounds that should be used in the simulated wastes, given that the original organic chelator compounds have degraded substantially?

- What will be the effect of dilution both on the radiolysis and on the thermal chemistry taking place in the waste?

- What is the effect of trace quantities of noble metals (Pd, Rh, and $\mathrm{Ru}$ ), silica, and metallic iron on the rate of gas evolution?

- What is the role of formate and oxalate in the generation of gases. 


\section{References}

Allemann, R. T. 1992. "Physical Mechanisms Contributing to the Episodic Gas Release from Hanford Tank 241-SY-101." In High Level Waste Management - Proceedings of the Third International Conference, Las Vegas, Nevada, April, 1992, American Nuclear Society Inc., La Grange, IL, 60525 and American Society for Civil Engineers, New York, New York, 10017.

Anantatmula, R. P. 1992. Status of Tank 241-SY-101 Data Analyses. WHC-EP-0584, Westinghouse Hanford Company, Richland, Washington.

Ashby, E. C., C. Jonah, D. Meisel, L. R. Pederson, and D. M. Strachan. 1992. Gas Generation and Retention in Tank 241-SY-101: A Summary of Laboratory Studies, Tank Data, and Information Needs, PNL-8124. Pacific Northwest Laboratory, Richland, Washington.

Babad, H., G. D. Johnson, Jr., D. A. Reynolds, and D. M. Strachan. 1992. The Hydrogen Program: The Present Understanding of Cyclic Venting Tanks. WHC-SA-1406-FP, Westinghouse Hanford Company, Richland, Washington.

Barney, G. S. 1976. Vapor-Liquid-Solid Phase Equilibria of Radioactive Sodium Salt Wastes at Hanford, ARH-ST-133, Atlantic Richfield Hanford Company, Richland, Washington.

Bouse, D. G. 1975. Thermal Conductivity of Hanford Waste Tank Solids and SX Tank Farm Soil Samples, ARH-CD-378. Atlantic Richfield Hanford Company, Richland, Washington.

Bryan, S. A., L. R. Pederson, and R. D. Scheele. 1992. "Slurry Growth and Gas Generation in Synthetic Hanford Waste," PNL-SA-21272. Pacific Northwest Laboratory, Richland, Washington.

Delegard, C. H., 1980. Laboratory Studies of Complexed Waste Slurry Volume Growth in Tank 241SY-101, RHO-LD-124. Rockwell Hanford Operations, Richland, Washington.

Herting, D. L., D. B. Bechtold, B. A. Crawford, T. L. Welsh, and L. Jensen. 1992. Laboratory Characterization of Samples Taken in May 1991 from Hanford Waste Tank 241-SY-101, WHC-SDWM-DTR-024 (Revision 0), Westinghouse Hanford Company, Richland, Washington.

Johnson, G. D., Jr. 1992. "Thoughts on What's Happening is Tank 101-SY." Presented to the Tanks Advisory Panel, Richland, Washington, June 17-19, 1992. Westinghouse Hanford Company, Richland, Washington.

Meisel, D., H. Diamond, E. P. Horwitz, C. D. Jonah, M. S. Matheson, M. C. Sauer, and J. C. Sullivan. 1991. Radiation Chemistry of Synthetic Waste, ANL-91/40, Argonne National Laboratory, Argonne, IL.

Reynolds, D. A. 1992. Tank 101-SY Window C Core Sample Results and Interpretation, WHC-EP0589, Westinghouse Hanford Company, Richland, Washington. 
Schulz, W.W., and D.M. Strachan. 1992. Minutes of the Tank Waste Science Panel Meeting March 25-27, 1992, PNL-8278, Pacific Northwest Laboratory: Richland, Washington.

Strachan, D. M. 1991. Minutes of the Tank Waste Science Panel Meeting February 7-8, 1991, PNL7709, Pacific Northwest Laboratory, Richland, Washington.

Strachan, D. M. 1992a. Minutes of the Tank Waste Science Panel Meeting July 9-11, 1991, PNL8048, Pacific Northwest Laboratory, Richland, Washington.

Strachan, D. M. 1992b. Minutes of the Tank Waste Science Panel Meeting November 11-13, 1991, PNL-8047, Pacific Northwest Laboratory, Richland, Washington.

Tye, R. P. 1969. Thermal Conductivity, Vol. 1, Academic Press, London.

Young, C. L. 1981. Oxides of Nitrogen, Vol. 8 of Solubility Data Series, Permagon Press, New York. 
Appendix A

Calculation of an Activation Energy from Tank Data 


\section{Appendix A}

\section{Calculation of an Activation Energy from Tank Data}

Waste height data from Tank 101-SY suggest that the rate of gas generation is constant with time, i.e. the rise in waste level is linear with time (see Figure 1). There appears to be no upward curvature to the data yet the temperature in the nonconvective layer of the tank increases approximately $6 \mathrm{~K}\left(12^{\circ} \mathrm{F}\right)$. Since the standard deviation in the fit of a straight line to the data is less than 5\% (excluding the downward curvature attributed to gas release), it suggests that if the rate increases with increasing temperature at the bottom of the tank then the rate increases less than the ability to detect it using the current measurement techniques (i.e., $<5 \%$ ). This change must be such that the ratio of the rate of gas generation at the beginning of the $100 \mathrm{~d}$ period $\left(R_{1}\right)$ to the rate at the end $\left(\mathbf{R}_{2}\right)$ is 1.05 or less. The Arrhenius expression is

$$
r=k \exp \left(-\frac{E_{A}}{R T}\right)
$$

and the ratio

$$
\ln \left(\frac{r_{2}}{r_{1}}\right)=\left(\frac{E_{A}}{R}\right)\left(\frac{1}{T_{1}}-\frac{1}{T_{2}}\right)
$$

or

$$
\ln \left(\frac{r_{2}}{r_{1}}\right)=\ln (1.05)=\left(\frac{E_{A}}{8}\right)\left(\frac{1}{324}-\frac{1}{330}\right)
$$

for the case of a $6 \mathrm{~K}$ increase in temperature. This yields an activation energy of about $7 \mathrm{~kJ} / \mathrm{mol}$. 


\section{Appendix B}

\section{Definitions of Abbreviations for Organic Species}




\section{Appendix B}

\section{Definitions of Abbreviations for Organic Species}

$\begin{array}{ll}\text { EA } & \text { ethanolammine } \\ \text { EAMA } & \text { ethanolamminemonoacetate } \\ \text { ED3A } & \text { ethylenediamminetriacetate } \\ \text { EDDA } & \text { ethylenediamminediacetate - can be symmetrical (s-) or unsymmetrical (u-) } \\ \text { EDMA } & \text { ethylenediamminemonoacetate } \\ \text { EDTA } & \text { ethylenediamminetetraacetate } \\ \text { HEDTA } & \text { 2-hydroxyethylethylenediamminetriacetate } \\ \text { IDA } & \text { iminodiacetate }\end{array}$

B.1 


\section{Distribution}

No. of

Copies

\section{OFFSITE}

12 DOE/Office of Scientific and Technical Information

J. Tseng

U.S. Department of Energy

EM-35

Trevion II

Washington, DC 20585-0002

C. S. Abrams

1987 Virginia

Idaho Falls, ID 83404

S. Agnew

Los Alamos National Laboratory

MS-C345, Group INC-4

P.O. Box 1664

Los Alamos, NM 87545

J. Antizzo

U.S. Department of Energy

EM-351

Trevion II

Washington, DC 20585-0002

E. C. Ashby

225 North Avenue

Boggs Chemistry Building

Georgia Institute of

Technology

Atlanta, GA 30332

K. Bandyopadhyay

Building 129

Brookhaven National Laboratory

Upton, NY 11973
No. of

Copies

N. E. Bibler

Westinghouse Savannah River

Bldg. 773A, Room 108

Aiken, SC 29802

J. O. Campbell

Oak Ridge National Laboratory

P.O. Box 2008, MS 6268

Oak Ridge, TN 37831-6268

F. N. Carlson

6965 North, 5th West

Idaho Falls, ID 83401

G. R. Choppin

Department of Chemistry B-164

Florida State University

Tallahassee, FL 32306

E. D. Collins

Oak Ridge National Laboratory

P.O. Box 2008

7930, MS-6385

Oak Ridge, TN 37831-6385

P. d'Entremont

Westinghouse Savannah River

P.O. Box 616, Bldg. 703-H

Aiken, SC 29802

R. Daniels

SAIC

20300 Century Blvd.

2nd Floor

Germantown, MD 20874

M. First

295 Upland Avenue

Newton Highlands, MA 02161

Distr. 1 
No. of

Copies

C. Grelecki

Hazards Research Corporation

200 Valley Rd, Suite 301

Mt. Arlington, 07856

E. J. Hart

2115 Hart Road

Port Angeles, WA 98362

P. Hogroian

SAIC

20300 Century Blvd., 2nd Floor

Germantown, MD 20874

E. P. Horwitz

Chemistry Division

Argonne National Laboratory

Argonne, IL 60439

A. Hoskins

WINCO, MS-5217

P.O. Box 4000

Idaho Falls, ID 83403-4000

B. S. Hudson

Lawrence Livermore National

Laboratory, L-221

P.O. Box 808

Livermore, CA 94550

M. S. Kazimi

Room 24-102

77 Massachusetts Avenue

Cambridge, MA 02139

P. Kiang

BDM, Trevion I, Suite 300

12850 Middlebrook Road

Germantown, MD 20874
No. of

Copies

L. Kovach

NUCON

P.O. Box 29246

Columbus, $\mathrm{OH} 43229$

B. R. Kowalsik

Chemistry Dept. BG-10

University of Washington

Seattle, WA 98195

T. S. Kress

P.O. Box 2009

MS 8088, Building 9108

Oak Ridge, TN 37381

T. E. Larson

Los Alamos National

Laboratory, M-1

MS C-920, P.O. Box 1663

Los Alamos, NM 87545

D. Meisel

Argonne National Laboratory 9700 South Cass Avenue

Argonne, IL 60439

D. T. Oakley

Los Alamos National

Laboratory

University of California, Suite 310

409 12th Street, SW

Washington, DC 20024-2188

F. L. Parker

Vanderbilt University

P.O. Box 1596, Station B

Nashville, TN 37235 
No. of

\section{Copies}

D. Ploetz

West Valley Nuclear

Services Co.

P.O. Box 191, MS 305

West Valley, NY 14171-0191

G. Powers

Design Science Inc.

163 Witherow Road

Sewickely, PA 15143

M. Reich

Building 129

Brookhaven National Laboratory

Upton, NY 11973

G. A. Russell

Department of Chemistry

Iowa State University

Ames, Iowa 50011-3111

J. Saveland

SAIC

20300 Century Blvd., 2nd Floor

Germantown, MD 20874

G. E. Schmauch

Air Products \& Chemicals, Inc.

7201 Hamilton Blvd.

Allentown, PA 18195-1501

A. Schneider

Massachusetts Institute of Technology

Department of Nuclear Engineering

Room 24-108

77 Massachusetts Avenue

Cambridge, MA 02139

W. W. Schulz

727 Sweetleaf Drive

Wilmington, DE 19808
No. of

Copies

B. Schutte

EG\&G Idaho, Inc.

P.O. Box 1625

Idaho Falls, ID 83415-3940

D. D. Siemer

WINCO

IRC, MS 2207

Idaho Falls, ID 83403

S. E. Slezak

Sandia National Laboratories, Division 6463

P.O. Box 5800

Albuquerque, NM 87185

H. Sullivan

Los Alamos National

Laboratory, N-6, MS-K557

P.O. Box 1664

Los Alamos, NM 87545

H. Sutter

SAIC

20300 Century Blvd., 2nd Floor

Germantown, MD 20874

T. Temple

U.S. Department of Energy,

Bldg. 703-H/115

P.O. Box A

Aiken, SC 29801

W. J. Thomson

Department of Chemical

Engineering

Washington State University

Pullman, WA 99164

E. Tuthill

Brookhaven National Laboratory

Upton, NY 11973

Distr.3 
No. of

\section{Copies}

A. S. Veletsos

5211 Paisley

Houston, TX 77096

G. B. Wallis

Thayer School of Engineering

Darmouth College

Hanover, NH 03755

H. Walter

U.S. Department of Energy

EM-343

Trevion II

Washington, DC 20585-0002

M. Walter

U.S. Department of Energy

EM-35

Trevion II

Washington, DC 20845-0002

D. Wiffen

U.S. Department of Energy

EM-35

Trevion II

Washington, DC 20585-0002

G. Woodall

U.S. Department of Energy, MS-1139

785 DOE Place

Idaho Falls, ID 83402

\section{ONSITE}

5 DOE Richland Field Office

R. F. Christensen, A4-02

R. E. Gerton, A5-21

G. Rosenwald, A5-21

B. J. Tucker, A4-35

Reading Room A1-65
No. of

Copies

30 Westinghouse Hanford Company

J. H. Appel, S4-58

R. P. Anantatmula, R2-11

H. Babad, B2-15

D. B. Bechtold, T6-50

R. M. Black, R1-19

T. M. Burke, H0-34

R. J. Cash, B3-68

C. Defigh - Price, R2-31

J. C. Fulton, R2-31

K. A. Gasper, B3-68

H. D. Harmon, R2-52

D. L. Herting, T6-50

J. D. Hopkins, R2-08

J. Jewett, T6-50

G. D. Johnson, L5-03

N. W. Kirch, R2-11

W. L. Knecht, H0-34

J. W. Lentsch, R2-78

R. M. Marusich, H5-32

N. G. McDuffie, R2-78

W. C. Miller, B1-58

J. C. Person, T6-50

J. G. Propson, R2-18

D. A. Reynolds, R2-11 (5)

M. H. Shannon, B1-35

D. D. Stepnewski, N1-31

52 Pacific Northwest Laboratory

R. T. Allemann, K5-19

R. M. Bean, P8-08

S. A. Bryan, P7-35

L. L. Burger, P7-25

J. A. Campbell, P8-08

J. B. Colson, K5-10

S. C. Goheen, P8-08

R. T. Hallen, P8-38

D. K. Hilliard, K2-50

B. M. Johnson, Jr., K5-02

M. R. Kreiter, K7-90

D. K. Lemon, K2-28

Distr.4 
No. of

Copies

L. G. Morgan, P8-07

L. R. Pederson, K2-44

R. D. Scheele, P7-25

G. F. Schiefelbein, P8-38

J. C. Spanner, K2-31

D. M. Strachan, K2-44 (25)
No. of

Copies
R. W. Stromatt, P7-22
D. S. Trent, K1-82
H. H. Van Tuyl, P7-22
T. W. Wood, K6-47
Publishing Coordination
Technical Report Files (5)

Distr.5 

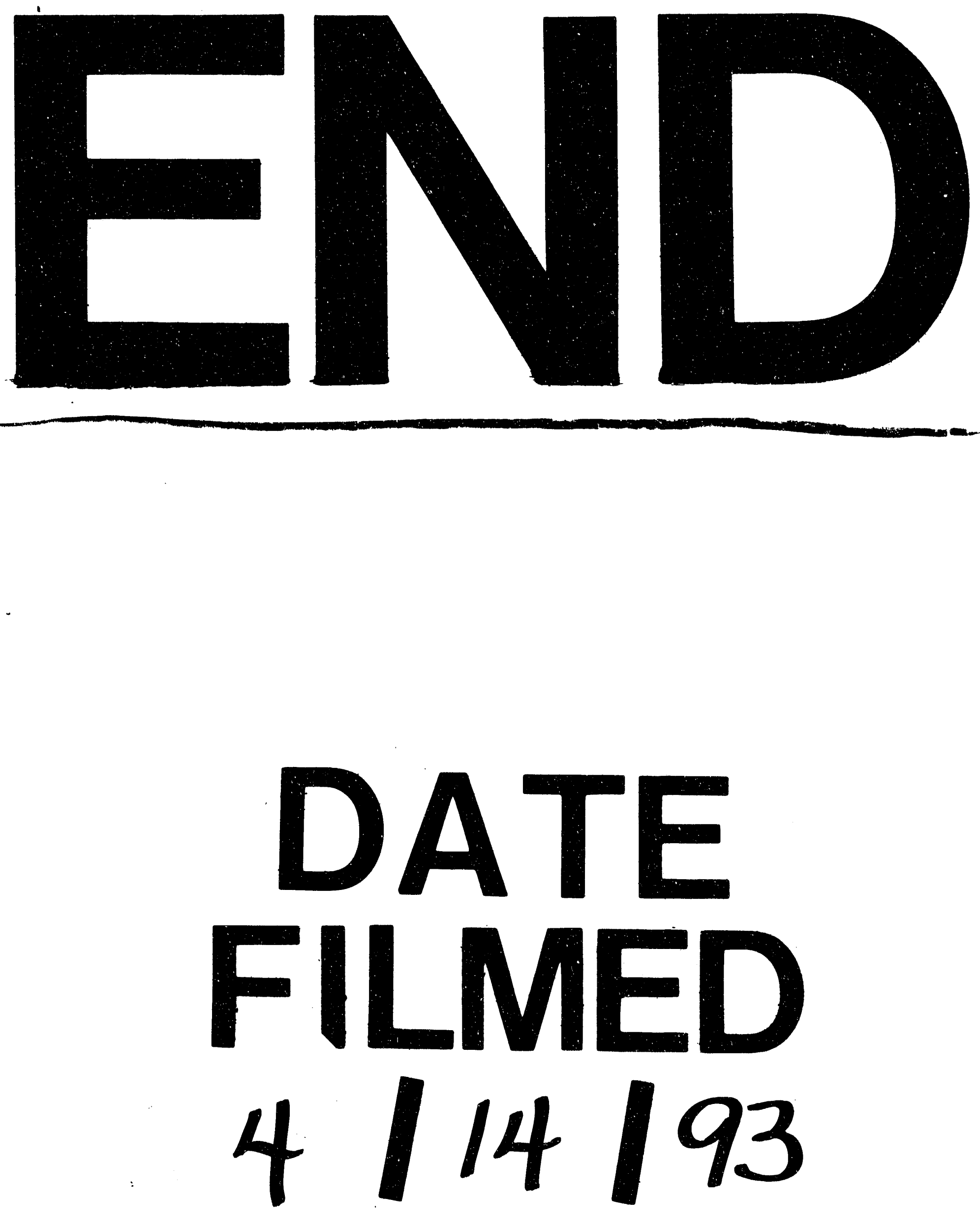
